\title{
¿QUÉ SE HA DICHO \\ SOBRE EL FUNCIONAMIENTO \\ DE LA JUSTICIA CIVIL EN CHILE? \\ APORTES PARA LA REFORMA
}

\section{¿WHAT HAVE BEEN TOLD ABOUT THE FUNCTIONING OF THE CIVILJUSTICE IN CHILE? CONTRIBUTIONS FOR THE REFORM}

\author{
Cristián Riego" \\ Ricardo Lillo"*..
}

\section{RESUMEN}

Durante los últimos años se ha ido generando un importante consenso sobre la necesidad de reformar la justicia civil, el cual se ha cristalizado en diversas propuestas que hasta el día de hoy se encuentra en discusión. Un análisis profundo acerca del funcionamiento de la justicia civil en el país, en particular una identificación bastante precisa de sus problemas, es una necesidad urgente de satisfacer si se espera llevar a buen puerto una política pública en la materia. Con estos fines, lo que pretende este trabajo es dar cuenta de las principales críticas realizadas en la literatura en la materia y sistematizarlas de acuerdo con cuatro categorías: barreras de acceso a la justicia civil, diseño procesal y la escrituración del procedimiento civil, falta de heterogeneidad del ingreso y la lentitud en la tramitación de estas causas. Por último, se identifican futuras líneas de investigación que permitan completar un diagnóstico mínimo que fortalezca la discusión sobre la reforma a la justicia civil en Chile.

Palabras clave: justicia civil, proceso civil, acceso a la justicia, demoras, delegación de funciones.

* Master of Laws (LL.M.) University of Wisconsin-Madison. Profesor, Facultad de Derecho de la Universidad Diego Portales. Dirección postal: República 112, Santiago, Chile. Correo electrónico: cristian.riego@udp.cl. Artículo recibido el 17 de abril de 2015 y aceptado para su publicación el 23 de julio de 2015

${ }^{* *}$ Master of Laws (LL.M), in Public Interest Law and Policy, University of California Los Angeles. Profesor, Facultad de Derecho de la Universidad Diego Portales. Dirección postal: República 112, Santiago, Chile. Correo electrónico: ricardo.lillo@mail.udp.cl. Artículo recibido el 17 de abril de 2015 y aceptado para su publicación el 23 de julio de 2015 . 


\begin{abstract}
In recent years, there is a growing consensus on the necessity of a civil justice reform. This consensus has crystallized into various proposals that until today are under legislative discussion. Notwithstanding, a deeper analysis on the functioning of the civil justice in the country, particularly the precise identification of its problems, is an urgent need to meet if we expect for a success of the public policy in this area. For these purposes, this article aims to account for the main critics that exist in the literature on the subject and systematize them according to four categories: existing barriers for accessing to civil justice, procedural design and the excessive written character of the civil procedure, lack of heterogeneity of civil filings, and the length of these cases. Finally, future research areas are identified to serve the necessity of the minimum diagnosis required to strengthen the discussion on civil justice reform in Chile.
\end{abstract}

Keywords: Civil Justice, Civil Procedure, Access to Justice, Delay, Delegation of judicial tasks.

\title{
I. INTRODUCCIÓN
}

Durante los últimos años, se ha ido generando un importante consenso en cuanto a la necesidad de reformar la justicia civil. Frente a una tarea de tal envergadura resulta evidente la necesidad de generar un vigoroso debate sobre diversos aspectos. Hasta ahora la discusión se ha referido a cuestiones como los valores que debe expresar el sistema y los modelos relevantes del derecho comparado. Sin perjuicio de la relevancia de lo anterior, creemos que un análisis profundo acerca del funcionamiento concreto de la justicia civil en el país, en particular una identificación bastante precisa de los problemas que en la actualidad presenta, es aún un elemento pendiente. Un buen diagnóstico parece ser uno de los requisitos básicos con miras a la elaboración de una propuesta apropiada que incorpore todos estos asuntos que el nuevo sistema debiera resolver.

Con estos fines, lo que pretende este trabajo es realizar una revisión bibliográfica exhaustiva y sistematizar lo que tanto la dogmática procesal nacional como autores provenientes de otras disciplinas, han dicho acerca del funcionamiento práctico del sistema de justicia civil chileno en los últimas tres décadas. En este sentido, aquí no se citan escritos de tipo meramente doctrinario sobre Derecho Procesal o descriptivos de su regulación en el código del ramo, sino solo aquellos donde se han hecho referencias a su funcionamiento en la práctica. 
Nos parece que esta información es la base mínima que con debiéramos contar, ya que a lo menos permitiría saber qué temas han sido estudiados, cuáles son sus conclusiones, qué datos tenemos y cuáles temas requieren de mayor investigación para poder desarrollar un diagnóstico que pueda servir de base para una propuesta que resulte constructiva.

La información que hemos revisado se refiere tanto a elementos del diseño del proceso civil, esto es a las normas y estructuras institucionales que lo conforman, como a su funcionamiento empírico. Si bien se trata de dos niveles diferentes, ambas cuestiones suelen mezclarse en los distintos trabajos y nos parecen de igual relevancia para una propuesta de reforma.

La doctrina en la materia, principalmente cercana al mundo del Derecho Procesal, en general no ha estado enfocada en identificar los problemas prácticos del actual modelo procesal civil. Han sido pocos los autores que han tenido una perspectiva crítica o evaluativa. Los pocos existentes se restringen a temas acotados en el contexto de trabajos de tipo dogmático. En este sentido, es difícil encontrar descripciones, evaluaciones, u opiniones acerca del funcionamiento del sistema ${ }^{1}$. Por el contrario, la mayor parte de las descripciones, opiniones y de la información empírica disponibles proviene de trabajos de profesionales interesados en la reforma judicial como política pública, a trabajos empíricos vinculados a procesos de reforma o a tareas de gestión de organismos públicos.

La literatura disponible ha abordado algunos problemas cuya prioridad ha estado vinculada a los propósitos específicos de cada estudio. Para efectos de su presentación, en este trabajo hemos ordenado los temas agrupándolos en cuatro categorías, a partir de las cuales se desarrolla este artículo.

Un primer problema que ha sido planteado reiteradamente por diversos autores se refiere a las diversas barreras para acceder a la justicia civil que la ciudadanía en general, y los sectores de menos recursos o menor integración social en particular, han venido experimentando al menos durante las últimas tres décadas. Sobre este problema existe alguna información empírica que ilustra cuales serían los problemas legales que las personas en condición de vulnerabilidad enfrentan y para los que no encuentran respuestas apropiadas.

Un segundo tema es la crítica de algunos aspectos del diseño procesal vigente, y en especial en cuanto a su carácter escrito. Este juicio normativo suele derivar en la descripción de algunas consecuencias prácticas de este

${ }^{1}$ La gran mayoría de los trabajos se centran en la explicación de los contenidos de la ley procesal con algunas explicaciones descriptivas de su funcionamiento en la práctica. Otro grupo de trabajos está dedicado a exposiciones o discusiones conceptuales, pero sin alusión crítica a la legislación o a lo que sucede en la realidad del proceso civil chileno. 
modelo procesal, como son el excesivo formalismo y la delegación de funciones judiciales en funcionarios subalternos. No obstante tratarse de un punto de vista bastante generalizado en la literatura, es poco lo que se ha documentado sobre el funcionamiento práctico del sistema escrito y sus prácticas asociadas. En este sentido, a pesar de que varios autores refieren críticas generales acerca de estos temas, no hemos encontrado estudios empíricos ni descripciones específicas acerca de cómo se conducen en realidad las diversas actividades y etapas del proceso civil, ni del modo en que se toman las decisiones en la práctica.

Un tercer tema es la excesiva utilización de la justicia civil en causas no contenciosas y ejecutivas o, desde otro punto de vista, de la baja proporción de causas contenciosas que son conocidas y resueltas en sede civil. Este problema se suele plantear vinculado a dos preocupaciones diferentes. Por una parte, se plantea como un tema de focalización de recursos públicos en asuntos de interés eminentemente privado y para los cuales tal vez el proceso judicial resulta demasiado complejo y costoso. Por la otra, se lo vincula a la carencia de mecanismos procesales apropiados para la resolución de asuntos no contenciosos que debieran tener soluciones diferenciadas, más sencillas y menos costosas. Sobre la existencia de este problema las opiniones son más bien unánimes y existen bastantes datos y evaluaciones del sistema que permiten no tan solo verificar esta situación sino, también, dar cuenta de cómo se ha acentuado en el tiempo.

En cuarto lugar, tal vez el problema que ha tenido mayor atención tanto en el ámbito dogmático como de estudios de carácter empírico es el de la demora o lentitud de los procesos civiles. Desde hace bastante tiempo este suele ser planteado como uno de los problemas del sistema chileno, existiendo alguna información empírica al respecto y que se analiza in extenso en este artículo.

El trabajo se divide en cuatro secciones. Una para cada uno de los elementos recurrentes en la doctrina en la materia, tal como fueron resumidos más atrás. Al final se agrega una sección de conclusiones que busca identificar las principales carencias de información con el objetivo de identificar futuras líneas de investigación que permitan completar un diagnóstico mínimo que fortalezca la discusión sobre la reforma a la justicia civil en Chile.

\section{ACCeso a la JUSTICIA CIVIL}

Una crítica constante al funcionamiento del sistema de justicia civil chileno está vinculada a la existencia de diversos obstáculos que dificultan el acceso de los ciudadanos al proceso jurisdiccional y, en especial, respecto de aquellos más débiles o menos integrados social y económicamente. 
El tema de la falta de acceso al sistema de justicia en general, y al civil en especial, se planteó con mucho énfasis en el periodo de la transición a la democracia en los tempranos años de la década de 1990. En ese lapso se exploraban diversas ideas destinadas a mejorar el sistema judicial, que había sido objeto de múltiples críticas debido a su desempeño durante la dictadura que concluyó en 1989.

Uno de los textos más representativos de esa época es un estudio colectivo que organizó y público el $\mathrm{CEP}^{2}$. La importancia de este estudio radica en que algunas de sus propuestas constituirían lo que sería el principal proyecto de reforma judicial del primer gobierno democrático, y de las que solo terminaron aprobándose unas pocas ${ }^{3}$.

El estudio del CEP identificó la falta de acceso de las personas más desaventajadas como uno de los principales problemas del sistema judicial chileno ${ }^{4}$. A partir de esta afirmación el estudio plantea, entre sus propuestas, la creación de una justicia de paz a partir de los juzgados de policía local ${ }^{5}$ y la reorganización de las corporaciones de asistencia judicial ${ }^{6}$.

Otro estudio que plantea el tema en términos generales fue realizado por Carlos Peña ${ }^{7}$. Este trabajo no se refiere específicamente al sistema de justicia civil, sino al conjunto del sistema judicial. Su planteamiento consiste en identificar algunos factores que han generado que los sectores pobres tengan dificultades para acceder a la justicia. En particular, se señalan tres: el primero estaría dado por el formalismo, la falta de adecuación legal y la falta de acceso a una atención profesional eficiente; el segundo sería la desconfianza de los sectores populares respecto del sistema de justicia y el tercero estaría constituido por el carácter represivo respecto de los pobres en el ámbito penal ${ }^{8}$.

Resulta llamativo que más allá de afirmaciones generales como las mencionadas, existe poco desarrollo acerca de cuáles son los obstáculos específicos que generan los problemas de acceso para las personas de menores recursos ante los tribunales civiles. El único trabajo que avanza en ese sentido es el de Jorge Correa y María Angélica Jiménez ${ }^{9}$, donde se plantea la existencia de lo que se califica como barreras estructurales

${ }^{2}$ ValenZuela (1991).

${ }^{3}$ Las más importantes fueron la creación de la Academia Judicial y la restricción de algunas facultades de la Corte Suprema. Entre ellas no se incluyeron reformas al proceso civil.

${ }^{4}$ Valenzuela (1991), p. 59.

${ }^{5}$ Op. cit., p. 66.

${ }^{6}$ Op. cit., p. 64.

${ }^{7}$ PeÑa (1993), pp. 285-424.

${ }^{8}$ Op. cit., p. 361.

${ }^{9}$ Correa y Jiménez (1977). 
para el acceso a la justicia no penal. Entre ellas se identifica como tema central la supresión de los tribunales de menor y mínima cuantía y la no creación de tribunales vecinales, a pesar de la existencia de múltiples proyectos que los propusieron. Se plantea que serían esos tribunales los que, funcionando de manera informal, rápida, con oralidad, inmediatez y publicidad, serían los llamados a atender los problemas de estos grupos de la población. Otro obstáculo estaría constituido por la necesidad de contar con los servicios de un abogado, cuestión que el trabajo desarrolla mediante una exposición de los servicios de asistencia gratuita del país a la época de su publicación. También se plantea como una categoría, el formalismo de la cultura judicial chilena, donde se incluye cuestiones como el lenguaje, las formas y los rituales que no son comprensibles para las personas comunes. Además, se identifica la ausencia de mecanismos de defensa de derechos colectivos. Finalmente, se menciona la excesiva duración de los procesos como un obstáculo al acceso ${ }^{10}$.

Pese al mayor desarrollo durante la década de 1990, la temática del acceso y sobre todo las propuestas para su ampliación, en especial bajo el formato de tribunales de pequeñas causas o mínima cuantía, tienen antecedentes anteriores a ese período ${ }^{11}$.

De la revisión de la literatura sobre la materia no hemos logrado identificar estudios empíricos que acrediten de manera precisa los obstáculos de acceso a la justicia civil. Sin embargo,una investigación que abarcó la relación entre sectores marginales y el sistema de justicia entregó algunos datos relevantes. Dicho estudio se llevó a efecto en 1993 y se repitió cuatro años después en $1997^{12}$. En los dos casos se trató de encuestas realizadas a habitantes de sectores populares urbanos.

Ambos estudios mostraron que la opinión de las personas encuestadas respecto de la justicia era mayoritariamente negativa, $82,85 \%$ en 1993 y $88 \%$ en 1997. A su vez, entre las opiniones negativas, la mayoría de ellas se referían a críticas por la lentitud, la ineficiencia y el carácter discriminatorio de la justicia en contra de los pobres. Empero, todas estas críticas son muy generales puesto que se refieren a todo el sistema de justicia que, en la percepción de los entrevistados, se identifica de manera importante con la justicia penal.

Una opinión que puede resultar relevante para la identificación de los obstáculos de acceso de personas de escasos recursos tiene relación

${ }^{10}$ Correa y Jiménez (1977), p. 79.

${ }^{11}$ Para un análisis histórico de las iniciativas destinadas a establecer mayor accesibilidad a la justicia civil, véase: CERDA (1997), pp. 355-378.

${ }^{12}$ Correa y Barros (1993); Barros (1997). 
con los abogados. Tanto en el estudio de $1993^{13}$ como en el de $1997^{14}$ los entrevistados manifestaron opiniones mayoritariamente negativas sobre estos. En particular, las críticas se vinculaban al costo que implicaba contratar sus servicios.

Además de opiniones, los estudios también tenían preguntas sobre experiencias concretas de los entrevistados y, en particular, sobre cuáles eran los problemas legales que habían experimentado. En el estudio de 1993 los problemas de tipo civil constituyeron el segundo grupo más importante después de los de tipo penal, por sobre los laborales y familiares, habiendo sido mencionados por un $24 \%$ de los encuestados. Dentro de estos, los más comunes eran los vinculados al arrendamiento de inmuebles, al consumo, a deudas impagas y a situaciones de herencia ${ }^{15}$. La situación cambió de manera muy notoria en el estudio de 1997, donde los problemas civiles pasaron a constituir los de mayor prevalencia con porcentajes muy superiores a los del estudio anterior. Así, por ejemplo, un $49,3 \%$ de los encuestados dijo tener problemas de consumo y un $47 \%$ dijo ser acreedor de deudas impagas ${ }^{16}$.

Quizá el dato más relevante, en cuanto a los problemas de acceso, lo constituye el bajo porcentaje de problemas declarados que los entrevistados dicen haber presentado formalmente ante el sistema de justicia. En el estudio de 1993, de los casos de tipo civil que los entrevistados mencionaron, solo un 16,6\% dijo haberlos denunciado ante alguna autoridad. Este porcentaje llama la atención puesto que es bastante menor a las acciones presentadas en las demás materias ( $41 \%$ en penal, $46,9 \%$ en materia familiar y $43,3 \%$ en materia laboral ${ }^{17}$. También se les preguntó sobre los asuntos que habían sido presentados ante un tribunal y, como es de esperar, en este caso el porcentaje es aún más bajo. De los casos civiles reportados solo un 8,9\% dijo haberlos judicializado. También en este punto, el porcentaje es mucho menor en lo civil que en el resto de las materias (14,5\% en penal, $43,3 \%$ en familia y $24,6 \%$ en laboral $)^{18}$. En el citado estudio de 1997 el aumento del porcentaje de personas que dijeron tener problemas de tipo civil estuvo acompañado de una disminución en la búsqueda de respuestas institucionales. El porcentaje de asuntos civiles presentados ante alguna autoridad bajó a solo un 10,5\%, y siguió siendo muy inferior al de las demás materias (43\% en penal, 37,7 en familia y

\footnotetext{
${ }^{13}$ Correa y Barros (1993), p. 45.

${ }^{14}$ Barros (1997), p. 19.

${ }^{15}$ Correa y Barros (1993), p. 71.

${ }^{16}$ Barros (1997), p. 28.

${ }^{17}$ Correa y Barros (1993), p. 75.

${ }^{18}$ Op. cit., p. 78.
} 
$35,9$ en materia laboral $)^{19}$. En cuanto al ingreso formal del asunto en un juzgado, en materia civil el porcentaje fue solo un $3,3 \%$ de los casos, muy por debajo de las otras materias $(16,4 \%$ en penal, $45,9 \%$ en familiar y 15,4 en laboral $)^{20}$.

Es interesante constatar que, aun cuando los dos estudios mencionados fueron realizados antes de las grandes reformas a la justicia penal -de familia y laboral- la disposición de las personas a llevar sus conflictos en esas materias ante el sistema de justicia parecía ser muy superior a la que manifiestan en materia civil. Una explicación posible a este fenómeno es que a pesar de los problemas que esas jurisdicciones tenían antes de las reformas de la década de 2000, durante la última parte del siglo xx se habían creado diversas instituciones que favorecían un acceso de la población en esas áreas específicas. Estamos incluyendo aquí instituciones como las policías, la Inspección del Trabajo, la Corporación de Asistencia Judicial, entre otras iniciativas creadas en esa época.

Por otra parte, parece importante constatar que ambos estudios dan cuenta de que los problemas propiamente civiles tienen una gran relevancia en cuanto al número de personas afectadas por ellos. Empero, estas necesidades legales insatisfechas parecen no ser percibidas como los más urgentes. Preguntados los entrevistados por cuáles eran aquellos asuntos prioritarios que debieran ser atendidos por los nuevos tribunales, la gran mayoría indicó que eran los del ámbito penal $\left(64,2 \%\right.$ en $1993^{21}$ y $69 \%$ en 1997) ${ }^{22}$. En cambio, los problemas de tipo civil se ubicaban en la última y penúltima prioridad en 1993 y 1997, con promedios de 8,9\% y 9\%, respectivamente. El único cambio significativo, estuvo dado por la mayor importancia que le asignaron a la solución de los problemas de consumo, que de no haber sido mencionados como prioridad en el estudio de 1993, pasaron a ser identificados por un 24,7\% de los entrevistados de $1997^{23}$.

El tema del acceso a la justicia volvió a surgir con gran énfasis en los últimos años de la década de 2000. En este sentido, en 2007 un grupo de académicos de la Pontificia Universidad Católica de Chile publicó una propuesta destinada al establecimiento de juzgados vecinales ${ }^{24}$ en la que diagnosticaron una falta de acceso para un conjunto de causas de índole vecinal y de menor cuantía ${ }^{25}$. No obstante, aquí no se profundizó la evaluación, sino tan solo, además de enunciar el problema, se atribuyó

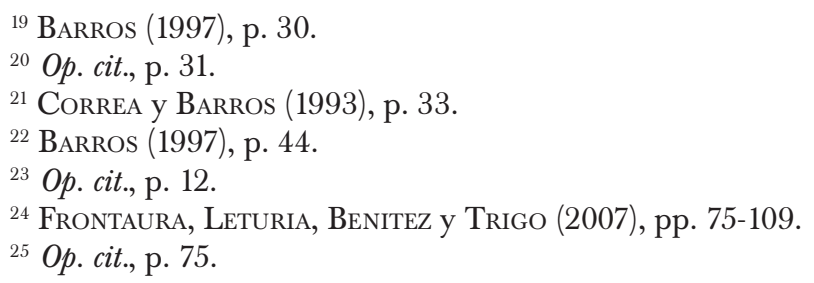


el fenómeno a los defectos en la inadecuación de los procedimientos, el formalismo y a la desconfianza de la población en el sistema de justicia. $\mathrm{El}$ avance y aporte de este trabajo, y otros semejantes ${ }^{26}$, consiste, más bien, en la formulación de propuestas. Como decíamos, en este caso en particular se planteó un proyecto para la creación de tribunales vecinales. Para ello, se incluyó desde una estimación de costos hasta la definición de una serie de aspectos orgánicos y relativos a los procedimientos que los juzgados deberían usar: orales, informales y rápidos ${ }^{27}$.

Durante el gobierno del presidente Sebastián Piñera, se planteó la necesidad de dar prioridad a una reforma sustantiva al sistema de justicia $\mathrm{civi}^{28}{ }^{2}$. Esta iniciativa consideró la creación de tribunales vecinales que, de una manera cercana a la ciudadanía, resolvieran los conflictos de pequeña escala y que hasta ese momento no encontraban una respuesta adecuada desde la institucionalidad tradicional ${ }^{29}$.

Por el contrario, el gobierno finalmente no presentó un proyecto de tribunales vecinales sino que implementó un proyecto piloto conocido como las Unidades de Justicia Vecinal ${ }^{30}$. Esta propuesta se fundamentó en dos tipos de críticas dirigidas a las respuestas que los mecanismos existentes daban a la solución de los conflictos "de la vida diaria" de las personas. Por una parte, se identificó una carencia de respuestas apropiadas y, por la otra, una excesiva estandarización de aquellas disponibles ${ }^{31}$.

A modo de conclusión, nos parece que la literatura da cuenta de una opinión bastante unánime sobre la existencia de una serie de obstáculos de acceso a la justicia civil. Sin embargo, al mismo tiempo no existe información empírica precisa acerca de sus contenidos, causas, prevalencia, frecuencia ni elementos ${ }^{32}$. Por otra parte, los estudios de percepción realizados a personas en situación de pobreza muestran que para estos grupos de la población los problemas civiles son relevantes y frecuentes aun cuando tengan una baja disposición a llevarlos ante el sistema judicial.

${ }^{26}$ Véase Godoy (2009).

${ }^{27}$ Frontaura, Leturia, Benitez y Trigo (2007), pp. 85-100.

${ }^{28}$ LIRA (2012), p. 8.

${ }^{29}$ Como antecedente de esta política se desarrolló un estudio que justificó esas conclusiones, aunque no se refiere a los problemas del proceso civil. Véase Ministerio DE Justicia (2011b).

${ }^{30}$ Una explicación detallada de sus objetivos, diseño y resultados en RIEGO y LILLO (2014), pp. 385-417.

${ }^{31}$ Ministerio de Justicia (2011a), p. 3.

${ }^{32}$ Para una visión dogmática de los costos y la demora como obstáculos al acceso a la justicia, véase Marinoni, PÉrez y NúÑEz (2010), pp. 186-188. 


\section{ESCRITURACIÓN Y DELEGACIÓN DE FUNCIONES}

Desde el punto de vista del diseño normativo el sistema procesal civil chileno ha sido criticado fundamentalmente por su excesiva escrituración. En general esta evaluación se formula a partir de la contradicción entre escrituración y oralidad como opciones alternativas en la construcción de los procedimientos desde la perspectiva de los llamados "principios formativos del procedimiento" 33 .

Gran parte de la doctrina que se ha pronunciado sobre este tema lo ha hecho desde un punto de vista dogmático. De esta manera, se ha concentrado en los principios que inspiraron el proceso civil chileno vigente desde principios del siglo xx y su evolución histórica, del papel que fuera entregado bajo este modelo al juez y los intervinientes, de los problemas del diseño normativo en relación con códigos más recientes en Derecho Comparado, y, aunque en menor medida, en cómo este diseño influenciaría el funcionamiento del sistema. No obstante, no hay estudios de carácter empírico que permitan dar cuenta de manera fehaciente de estos problemas, al menos en el ámbito civil ${ }^{34}$.

La crítica al carácter escrito del procedimiento se concentra en dos momentos. El primero se generó a partir de los primeros años de la transición a la democracia mediante una discusión abierta sobre la necesidad de reformar el sistema de justicia y donde se exploraron de manera crítica sus diversos componentes, tal como nos hemos referido en el acápite anterior. El segundo, en el que la literatura se focalizó en la escrituración del procedimiento civil se produjo una vez finalizados los procesos de reforma en otras áreas (penal, laboral, familia, etc.) a fines de la década de 2000. Este nuevo movimiento de reforma se cristalizó principalmente en la elaboración de un nuevo código del ramo, y que culminó con la elaboración del actual proyecto de nuevo Código Procesal Civil que se encuentra en discusión parlamentaria hasta la fecha.

Dentro del primer momento, ya en el estudio del CEP elaborado en la década de 1990, y citado en el acápite anterior, se critica el carácter escrito del procedimiento civil y se plantea que la disgregación de los trámites necesarios y su duración han ido generando el fenómeno de la "desaparición" del juez (salvo en lo que se relaciona con la dictación de las resoluciones). 419-443.

${ }^{33}$ Véase, por ejemplo, NúÑEz (2007), pp. 683-686; Silva y Domínguez (2006), pp.

${ }^{34}$ Por el contrario, las consecuencias de la escrituración como la falta de inmediación y delegación de funciones fueron ampliamente acreditados en la época de la década de 1990 con motivo de los primeros trabajos con miras a la reforma procesal penal. Véase Jiménez, Horvitz, Vargas, Mera y Riego (1994). También: Jiménez y Riego (1994). 
En relación con lo anterior, se señala que la intermediación y delegación de funciones que se ha impuesto en el procedimiento civil, incluso con el apoyo de expresas normas legales, afectarían actividades tan centrales como la prueba, en las que resulta fundamental una intervención directa del juez que debe tomar las decisiones ${ }^{35}$. Luego, justamente esta falta de contacto del juez con la prueba se vería agravada como producto de la dispersión de trámites y la excesiva duración de los procedimientos ${ }^{36}$. Se plantea, por último, que la situación generada por todos estos problemas ha producido una pérdida de confiabilidad en la administración de justicia ${ }^{37}$.

En la misma línea se manifestaron otros autores de ese periodo como Raúl Tavolari ${ }^{38}$, Juan Enrique Vargas y Jorge Correa. Estos dos últimos, en un estudio que abarcó diversas áreas del sistema judicial, describían al procedimiento civil como en extremo formalista producto de su carácter escriturado. En este sentido, sus críticas apuntaban a la falta de inmediación, señalando que la mayoría de las decisiones quedaban en manos de funcionarios inferiores, siendo solo ratificadas por el juez con su firma, y favorecida por un excesivo y demoroso recurso a la segunda instancia. Agregan, además, que todos los trámites orales incorporados a los procedimientos civiles se habían transformado en la protocolización de antecedentes escritos y que, en particular, se habría desvirtuado el llamado a conciliación transformándose en un mero trámite ${ }^{39}$.

En un periodo intermedio, y como producto de las discusiones que estaban teniendo lugar a propósito del proceso de reforma del sistema de justicia penal, Alex Caroca ${ }^{40}$ escribió un trabajo donde formula una crítica muy sustantiva al diseño del proceso civil chileno a partir de las normas de derechos humanos a que nuestro país se ha obligado por medio de diversos tratados internacionales. Plantea un análisis histórico de la estructura del procedimiento civil chileno y lo caracteriza como de origen medieval ${ }^{41}$. Las características específicas que considera problemáticas coinciden con las planteadas por otros autores, pero tienen algunos énfasis diferentes que vale la pena resaltar. De esta manera, para el autor, lo central es que las reglas procedimentales están orientadas fundamentalmente a

${ }^{35}$ VAlenZuela (1991). p. 12

${ }^{36}$ Ibid.

${ }^{37}$ Ibid.

${ }^{38}$ Raúl Tavolari afirma que el proceso civil chileno es "desesperadamente escrito" (citando a Eduardo Couture sin referencia) y defiende la necesidad de introducir la oralidad siguiendo el ejemplo uruguayo. Véase TAVOLARI (1994), pp. 60-61.

${ }^{39}$ Vargas y Correa (1995), p. 39.

${ }^{40}$ Caroca (1997).

${ }^{41}$ Op. cit., pp. 15-16. 
gobernar la producción de las actas y al hecho de que solo lo que en ellas consta puede ser objetivo de consideración por el juez en su decisión ${ }^{42}$. Además, plantea la falta de inmediación ${ }^{43}$, la división del proceso en una serie de fases separadas, la excesiva duración y la existencia de un sistema de impugnaciones demasiado amplio, aun para resoluciones de poca importancia ${ }^{44}$.

Pero, además de reiterar esta apreciación negativa que ya venía siendo formulada, Alex Caroca plantea otra crítica que resulta novedosa: el proceso civil chileno sería gobernado por un carácter excesivamente privado. Esto, según este autor, se traduciría en una extensión excesiva del principio dispositivo que llevaría a que las partes asuman un total control del avance del proceso. Asimismo, no niega que en el proceso civil el interés privado deba ser reconocido, pero plantea que la regulación y la práctica en el ámbito nacional han llevado esta noción a una versión extrema que operaría en perjuicio de una actividad proactiva de los tribunales en el avance de los procesos ${ }^{45}$.

Posteriormente vuelve a surgir con fuerza la crítica a la escrituración, en especial en los años posteriores a la reforma procesal penal, donde comienza la discusión del actual proyecto de código ${ }^{46}$. Estas críticas se refieren tanto al diseño normativo como al funcionamiento práctico del modelo vigente, el cual se vería muy influenciado por la centralidad del expediente. Así, por ejemplo, incluso cuando el actual Código de Procedimiento Civil estableció actuaciones orales en la regulación del procedimiento sumario, al permitir la ley la realización de minutas escritas en la práctica la oralidad sería nula ${ }^{47}$.

En este mismo sentido, Diego Palomo analiza la actividad probatoria en el actual proceso civil chileno y plantea que en él se aleja al juez de la prueba transformándolo en lector de evidencias en cuya producción no ha participado ${ }^{48}$. Señala, además, que esto se vería favorecido, también, por la disgregación y desconcentración de los actos procesales ${ }^{49}$. Luego del distanciamiento del juez y la prueba, se produce la perdida de "visibilidad" del juez, esto es, del contacto con las partes y sus abogados.

${ }^{42}$ Caroca (1997), p. 16.

${ }^{43}$ Op. cit., p. 17.

${ }^{44}$ Op. cit., p. 18.

${ }^{45}$ Op. cit., pp. 19-20.

${ }^{46}$ Véase Palomo (2005), pp. 171-197; Palomo (2010), pp. 465-524; Domínguez (2007), pp. 595-598; ONFray, p. 78.

${ }^{47}$ Domínguez (2007), p. 595.

${ }^{48}$ Palomo (2005), p. 173.

${ }^{49}$ Ibid. 
Como una derivación de la crítica que recae sobre el carácter escrito del sistema surge una segunda cuestión de igual relevancia, la delegación de funciones ${ }^{50}$. Justamente en lo referido a la actividad probatoria, la estructura escrita y desconcentrada del proceso civil chileno ha provocado un distanciamiento del juez y la prueba, la que por regla general será recibida y producida por otros intervinientes tales como receptores u otros funcionarios del tribunal (incluyendo algunos no letrados). El juez, en cambio, se centraría en su labor sentenciadora, la que aun contando con toda su atención, se vería perjudicada mediante un juicio fáctico elaborado sobre la base de una actividad probatoria deficiente, caracterizada como no suficientemente seria ${ }^{51}$.

La doctrina, entonces, parece bastante de acuerdo en que las características de escrituración y desconcentración del procedimiento civil han generado una práctica común donde los casos son tramitados bajo una serie de actos separados en el tiempo y desarrollados por funcionarios distintos al juez, quien solo dictará sentencia después de un largo tiempo basándose para ello en la revisión de un expediente que contendrá las pruebas sin que las haya conocido directamente. A su vez, las partes no tienen posibilidades efectivas de tener contacto con el juez durante el procedimiento. En fin, la opinión es bastante unánime en la identificación de este problema y plantea la necesidad de una reforma hacia la oralidad con la finalidad de resolverlo.

\section{EL USO DEL SISTEMA PARA CAUSAS NO CONTENCIOSAS. LA SOBRECARGA Y LA FALTA DE HETEROGENEIDAD DE LA DEMANDA}

Otro importante tema que suele ser señalado como uno de los factores críticos de la justicia civil chilena, es la excesiva utilización de los recursos del sistema en causas donde no hay un conflicto de relevancia jurídica $\mathrm{y}$, por lo tanto, susceptibles de ser solucionadas mediante una decisión jurisdiccional. Desde otro punto de vista, se destaca la baja proporción de causas realmente contenciosas que son conocidas y resueltas en dicha sede $^{52}$.

El problema sería entonces que, en vez de abocarse a verdaderos conflictos de relevancia jurídica, se estarían utilizando los costosos recursos

\footnotetext{
${ }^{50}$ Palomo (2005), p. 174. Véase, también Onfray (2010), p. 175.

${ }^{51}$ Palomo (2007), pp. 360-363.

${ }^{52}$ Ministerio de Justicia (2012), pp. 14-15. Véase también García y Leturia (2005), p. 15; Vargas (2006), p. 153; García y Castro (2006), p. 36; Vargas (2013), p. 193.
} 
del sistema en atender otro tipo de asuntos. En estos, normalmente, la función que realizarían los jueces sería más bien de tipo administrativo o notarial y, en general, restringirían el tiempo que podrían dedicar a resolver causas declarativas ${ }^{53}$.

Estas causas, que como veremos, representarían la gran proporción del ingreso civil en el ámbito nacional, serían en su mayoría juicios ejecutivos. El problema sería que en estos, solo una pequeña fracción corresponde a causas donde hay un verdadero conflicto jurídico sometido al conocimiento del tribunal. Por el contrario, en el resto, se trataría de causas sin verdadera oposición y donde el tribunal es utilizado como el mecanismo idóneo para cobrar y hacer efectivo un título ejecutivo. En este sentido, muchas de estas causas serían gestiones preparatorias de la vía ejecutiva.

Tal como da cuenta el Mensaje que acompañó el proyecto de nuevo Código Procesal Civil, los efectos de este fenómeno no se limitan a la saturación del sistema o al uso ineficiente de los recursos sino que, también, afectarían la labor jurisdiccional que se vería postergada por la carga de trabajo para los jueces el asumir dichas tareas. De esta manera, se señala, que todo el esfuerzo invertido en la continua preparación de los magistrados, así como su inspiración y vocación, se ven afectados seriamente por la realización de actividades alejadas del ejercicio en propiedad de la función jurisdiccional ${ }^{54}$.

Se ha criticado que estas necesidades de carácter administrativo y notarial que estarían siendo satisfechas por nuestros jueces, tienen como beneficiarios a grandes empresas e instituciones financieras que utilizan al sistema mediante grandes agencias de cobranzas para la tramitación de causas masivas, pero no al ciudadano común y corriente. Esto, por supuesto, daría cuenta de un problema desde la perspectiva del acceso a la justicia ${ }^{55}$. Así, y a modo meramente ejemplar, datos de 1996 para el $6^{\circ}$ Juzgado Civil de Santiago mostraban que el 36\% de los demandantes eran bancos e instituciones financieras, $10,3 \%$ eran casas comerciales, el $36,2 \%$ otras sociedades y las personas naturales no representaban más

${ }^{53}$ Vargas y Correa (1995), p. 40. Véase también Mery (2006), p. 107; Correa, Peña y Vargas (1999), p. 9; García y Leturia (2006a), p. 354; García y Leturia (2005), p. 16; VARGas (2005), pp. 10-11; Ried (2006), p. 489; Vial (2006), pp. 17-18; Villalobos (2009), pp. 13-14; Núñez, Pérez y Vargas (2013), p. 84.

${ }^{54}$ Ministerio de Justicia (2012), pp. 14-15.

${ }^{55}$ Valenzuela (1991), pp. 59-60. Véase también Mery (2006), p. 108; Vargas, Peña y Correa (2001), p. 91. En este mismo sentido y, en particular, respecto al ingreso de causas masivas de parte de empresas de cobranza, véase: Nuñez, Pérez y Vargas. (2013), pp. 103-108. 
que el 17,4\% del tota ${ }^{56}$. La falta de datos, actualizados y representativos, es una clara señal de la necesidad de profundizar la investigación en este tema.

La poca heterogeneidad del ingreso, entendiendo por tal la excesiva uniformidad de los asuntos que son mayormente conocidos por el sistema, causas sin un verdadero conflicto entre partes, sería un problema de larga data. De esta manera, ya en 1989 se decía que las causas "no jurisdiccionales" representaban el 63,8\% de los ingresos civiles (32,7\% gestiones preparatorias y un $31,1 \%$ de materias voluntarias), y un porcentaje similar respecto de las causas terminadas. Dentro del total de causas contenciosas ingresadas de ese año, el 24,3\% eran juicios ejecutivos y el 47,5\% gestiones preparatorias del juicio ejecutivo $(71,9 \%$ en total), respecto las cuales hay que tener en consideración que solo serán contenciosas en la eventualidad que se opongan excepciones ${ }^{57}$. Más allá de lo anterior, se desconoce que este problema haya motivado otros movimientos o intentos previos de reforma al actual código de procedimiento civil en dicha época.

Esta situación se ha mantenido en el tiempo. De esta manera, Rafael Mery en 2006 destacaba que las causas voluntarias y gestiones preparatorias donde no hay conflicto alguno ocupaban un lugar importante en el total de ingresos civiles ${ }^{58}$. De acuerdo con este autor, en la actualidad nuestros tribunales de justicia se dedican casi exclusivamente a la cobranza judicial en procesos que no revisten mayor complejidad, pero que implican un número importante de gestiones y actuaciones que congestionan los tribunales civiles ${ }^{59}$.

En consecuencia, los datos presentados por Rafael Mery confirman la apreciación de que estamos frente a un problema que viene de antiguo. Así, si en Santiago en 1981 el 68,1\% de las causas ingresadas eran cobranzas judiciales tramitadas bajo procedimientos ejecutivos o gestiones preparatorias, entre 1998 y 2003 el porcentaje era aún mayor.

${ }^{56}$ Vargas, Peña y Correa (2001), p. 92. Estos autores también dan cuenta de que además de representar solo el 17\%, las causas presentadas por personas naturales en la muestra utilizada correspondían en más de un 70\% a cuatro personas que actuarían en comisión de cobranza de los mismos grandes acreedores.

${ }^{57}$ Vargas y Correa (1995), p. 40. Véase también Peña (1993), pp. 322-323.

${ }^{58}$ Mery (2006), p. 108.

${ }^{59} \mathrm{Ibid}$. En este mismo sentido véase García y Leturia (2006), p. 352. 
GRÁFICO 1

GeSTIONES PREPARATORIAS y JUICIOS EJECUTIVOS

SOBRE EL TOTAL DE INGRESOS CIVILES DE SANTIAGO

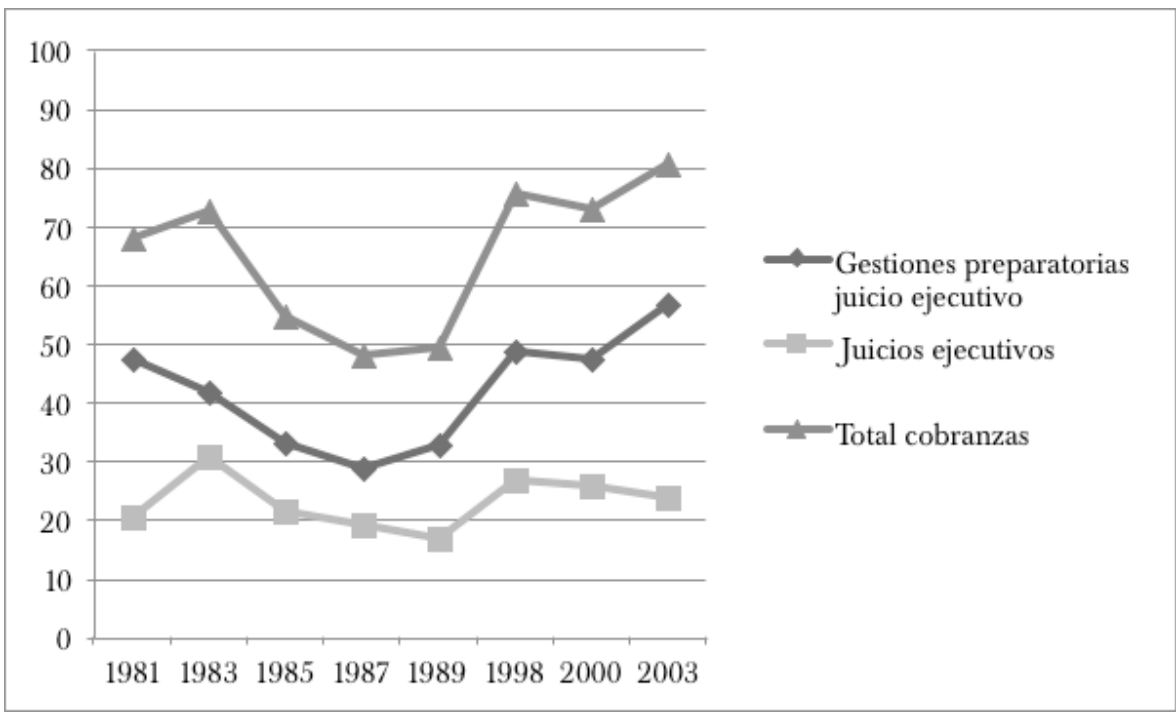

Fuente: Elaboración propia basada en datos de VARgas y CoRREA (1995); Mery (2006).

A mayor abundamiento, un estudio realizado por Juan Enrique Vargas, Carlos Peña y Jorge Correa Sutil en 1999 mostraba que entre el periodo 1977-1995 el promedio de causas de cobranzas judiciales en Santiago alcanzaba el $61 \%$ del total de las causas contenciosas ingresadas en sede civil, con un mínimo de $48 \%$ en 1987 y un máximo de $77,11 \%$ en $1982^{60}$. De manera similar, otros estudios mostraban que el promedio obtenido en el lapso entre 1995 y 2003 también era de 61\% de cobranzas respecto al total de los ingresos civiles ${ }^{61}$.

Datos más recientes muestran una realidad muy similar. En 2005 se iniciaron en Chile 966.930 causas civiles, de las cuales 712.278 correspondieron solamente a gestiones preparatorias de la vía ejecutiva y juicios ejecutivos, lo que corresponde a un 73,7\% del total de los juicios civiles ${ }^{62}$. Por su parte, en 2008 el 61\% del total correspondió a procedimientos ejecutivos mientras que las gestiones preparatorias (junto con medidas prejudiciales) ocupaban el 30\%63.

${ }^{60}$ Correa, Peña y Vargas (1999), p. 10. Véase también Vargas, Peña y Correa (2001), p. 90.

${ }^{61}$ García y Leturia (2006a), p. 353. Véase, además, García y Leturia (2005), p. 15.

${ }^{62}$ Ried (2006), p. 489.

${ }^{63}$ VARGAS (2011), p. 479. 
Pero, además, del total de causas que no eran gestiones preparatorias de la vía ejecutiva o ejecutivas propiamente tales, una importante fracción serían asuntos voluntarios. En este sentido, entre el periodo 19952003, el promedio de estas fue de $15 \% 0^{64}$ y en 2005 continuaba siendo un $14,7 \% \%^{65}$.

Luego, en 2008, descontando las causas tramitadas bajo procedimiento ejecutivo y medidas prejudiciales (que en conjunto representaban el $91 \%$ del ingreso), aquellas voluntarias ocupaban una proporción mayor $(5 \%)$ que las tramitadas bajo procedimientos típicamente contenciosos como el ordinario y sumario, que ocupaban solo el $2 \%$ del total de in$\operatorname{gresos}^{66}$.

Como vemos entonces, gran parte del ingreso históricamente ha estado representado en su mayoría por asuntos de carácter no contencioso, en particular de gestiones preparatorias de la vía ejecutiva y causas voluntarias. Si bien en principio los juicios ejecutivos podrían ser contenciosos, en particular si es que se hubiesen interpuesto alguna de las excepciones del art. 464 del Código de Procedimiento Civil, de acuerdo con la información existente es muy excepcional que esto ocurra. De acuerdo con Juan Francisco García y Francisco Javier Leturia, la frecuencia de con que ello ocurriría (la oposición), sería en no más del 15\% de las cobranzas (basándose para ello en datos del Derecho Comparado) ${ }^{67}$.

En un estudio realizado por el CEJA en 2009, se señala que del total del ingreso de causas civiles en Santiago aquellas tramitadas en procedimiento ejecutivo alcanzaron el $96,45 \%$. De ellas, la gran mayoría correspondía a juicios ejecutivos propiamente tales (70,55\%), y el resto eran gestiones preparatorias de la vía ejecutiva $(25,89 \%)$. En cambio, las causas tramitadas en procedimiento ordinario representaban tan solo el $1,46 \%$ y en sumario el $0,98 \%$. Por último, y a diferencia de otros estudios, se da cuenta de una proporción muy marginal de las denominadas gestiones voluntarias, las que alcanzarían el 0,54\% del total de ingre$\operatorname{sos}^{68}$.

En el estudio del CEJA se analizan, además, los tipos de término en el procedimiento ejecutivo para 2009 y 2010 . Aquellos asociados a las causas sin oposición alcanzaban el 98,1\% en 2009 y 97,8\% en 2010 del total de causas acabadas. Por el contrario, los casos con oposición de excepciones, es decir, aquellas que tendrán un carácter contencioso, y siendo aún menos

${ }^{64}$ García y Leturia (2006a), p. 354.

${ }^{65}$ García y Castro (2006), p. 36.

${ }^{66}$ VARgas (2011), p. 479.

${ }^{67}$ García y Leturia (2006a), p. 401.

${ }^{68}$ Centro de Estudios de Justicia de las Américas (2011), p. 15. 
que lo que veíamos en el trabajo de Juan Francisco García y Francisco Javier Leturia, alcanzaban menos del $2 \%$ de los $\operatorname{casos}^{69}$.

Los estudios citados presentan la limitación de referirse solo a juzgados civiles de Santiago. Aunque esta jurisdicción tenga la mayor cantidad de ingresos, ello no significa que pueda ser utilizada como representativa de lo que ocurre en el ámbito nacional. El único estudio que ha sido realizado una estimación de tal tipo es de la consultora EMG sobre la base de datos proporcionados por la Corporación Administrativa del Poder Judicial. En él aparece que cuatro de las cinco materias principalmente ingresadas en el ámbito nacional se relacionan con causas que se tramitan bajo el procedimiento ejecutivo o son gestiones preparatorias de la vía ejecutiva. De hecho, estas cuatro materias ocupan el 77,8\% del ingreso en este periodo, cifra bastante cercana a lo que hemos visto en otros estudios respecto de Santiago (tabla 1$)^{70}$.

TABLA 1

INGRESO POR MATERIAS SELECCIONADAS PERÍODO 2000-2010

\begin{tabular}{lcc}
\hline \multicolumn{1}{c}{ Materia } & Ingreso total & \% del ingreso \\
\hline Cobro de pagaré & 5.912 .245 & 50,3 \\
Citación confesión de deuda & 2.300 .077 & 19,6 \\
Notificación protesto de cheque & 603.089 & 5,1 \\
Pedimento minero(concesión de exploración) & 433.490 & $3,7^{71}$ \\
Cobro de letra de cambio & 325.366 & 2,8 \\
Otras & 2.185 .486 & 18,6 \\
\hline
\end{tabular}

Fuente: EMG Consultores (2012), p. 32.

También existe un estudio realizado por la Pontificia Universidad Católica de Valparaíso que se refiere a algunos tribunales específicos del país y seleccionados para el mismo periodo 2000-2010:

${ }^{69}$ Centro de Estudios de Justicia de las Américas (2011), pp. 34-36.

${ }^{70}$ EMG Consultores (2012), p. 32.

${ }^{71}$ De acuerdo con este estudio, el porcentaje obtenido por el pedimento minero se concentra particularmente en la zona norte de Chile, y se explican por un significativo número de causas ingresadas en las regiones de Tarapacá, Antofagasta, Coquimbo y por sobre todo, Atacama, las concesiones mineras superan a cobro de pagaré como materia principal en las causas ingresadas a tribunales de la jurisdicción de la Corte de Apelaciones de Copiapó. Véase Ibid. 
TABLA 2

CANTIDAD Y PORCENTAJES DE CAUSAS

POR TIPO DE PROCEDIMIENTO EN TRIBUNALES SELECCIONADOS

\begin{tabular}{|c|c|c|c|c|c|c|}
\hline \multirow{2}{*}{$\begin{array}{l}\text { Procedimiento } \\
\text { Ejecutivo }\end{array}$} & \multicolumn{2}{|c|}{$\begin{array}{c}3^{\text {er }} \text { Juzgado Civil } \\
\text { de Valparaíso }\end{array}$} & \multicolumn{2}{|c|}{$\begin{array}{c}2^{\circ} \text { Juzgado Civil } \\
\text { de San Miguel }\end{array}$} & \multicolumn{2}{|c|}{$\begin{array}{c}\text { Juzgado de Letras } \\
\text { y Garantía } \\
\text { de Quintero }\end{array}$} \\
\hline & 25.188 & $55,8 \%$ & 77.645 & $44,5 \%$ & 2.012 & $39,0 \%$ \\
\hline Especial & 201 & $0,4 \%$ & 270 & $0,2 \%$ & 258 & $5,0 \%$ \\
\hline \multicolumn{7}{|l|}{ Gestiones preparatorias } \\
\hline y Medidas prejudiciales & 13.270 & $29,4 \%$ & 82.553 & $47,3 \%$ & 1.019 & $19,7 \%$ \\
\hline Ordinario & 1.496 & $3,3 \%$ & 3.889 & $2,2 \%$ & 361 & $7,0 \%$ \\
\hline Sumario & 2.444 & $5,4 \%$ & 4.472 & $2,6 \%$ & 639 & $12,4 \%$ \\
\hline Voluntario & 2.530 & $5,6 \%$ & 5.582 & $3,2 \%$ & 871 & $16,9 \%$ \\
\hline Total & 45.129 & $100,0 \%$ & 174.411 & $100 \%$ & 5.160 & $100 \%$ \\
\hline
\end{tabular}

Fuente: Pontificia Universidad Católica de Valparaíso (2012), p. 23.

Pareciera que el conjunto de estudios reseñados constituyen evidencia suficiente de que la gran mayoría de causas civiles está constituida por asuntos ejecutivos o de cobranza, que solo en ocasiones presentan verdaderos conflictos entre partes. La gran cantidad de ingresos de este tipo de causas habría generado la congestión o sobrecarga de nuestros juzgados.

Para Raúl Núñez, Álvaro Pérez y Macarena Vargas, esta sobrecarga se debería a la utilización de los tribunales civiles, no como un espacio jurisdiccional, sino, principalmente, como una instancia burocrática que en gran medida realiza trámites:

i) que son meras formalidades para iniciar la ejecución;

ii) para iniciar una ejecución que concluye por acuerdo de las partes;

iii) para iniciar y proseguir la ejecución sin trabarse un procedimiento contencioso por no haber oposición del ejecutado.

Esto se reflejaría en que el porcentaje de las causas ejecutivas que son falladas, no llegaría al 3\% de las ingresadas. Además, algunos factores que contribuirían a esta situación serían: la rigidez en procedimientos del Servicio de Impuestos Internos que provoca que cientos de miles de causas al año se inicien, pero sin que el acreedor tenga realmente la intención de continuar la tramitación, la gratuidad en los trámites judiciales civiles; el escaso conocimiento público sobre atribuciones de empresas de cobranza y receptores y la escasa profesionalización de actores privados no oficiales ${ }^{72}$.

72 NúÑez, Pérez y Vargas (2013), pp. 84-86. De forma adicional, estos autores hacen una completa descripción del modelo operacional del tribunal civil para la tramitación del procedimiento ejecutivo. Véase op. cit., pp. 90-100; Pontificia Universidad Católica de Valparaíso (2012), pp. 13-14. 
Esta sobrecarga, que suele plantearse como una dificultad para el adecuado funcionamiento de la justicia civil, pareciera vincularse a estos tipos de problemas más que con una necesidad de aumentar de manera sustantiva el número de juzgados o jueces ${ }^{73}$. De hecho, el propio proyecto de nuevo Código Procesal Civil considera esta recarga como uno de los elementos del diagnóstico que fundamentan la reforma y, por lo mismo, propuso la creación de un sistema de cobranza de tipo administrativo que libere los recursos propiamente judiciales para la resolución de los asuntos contenciosos, aunque sin éxito hasta ahora en la discusión legislativa ${ }^{74}$.

Más allá de la heterogeneidad y cooptación del sistema por parte de las cobranzas, parece relevante constatar también que en las últimas décadas se ha producido un aumento relevante del volumen total de causas en los tribunales civiles. Existe un estudio de estimación de ingresos de causas civiles encargado por el Ministerio de Justicia y publicado en 2012. De acuerdo con este, el crecimiento del ingreso en el período 2000-2010 fue de un $239 \%$ con una tasa de crecimiento anual promedio de $13 \%$. A mayor abundamiento esta tendencia creciente estaría presente también en el ámbito de cada una de las regiones del país (con la excepción de la Región de Los Ríos) ${ }^{75}$.

GrÁFICO 2

CANTIDAd total y TASA DE CRECimiento DE INGRESOS CIVILES PERÍODO 2000-2010

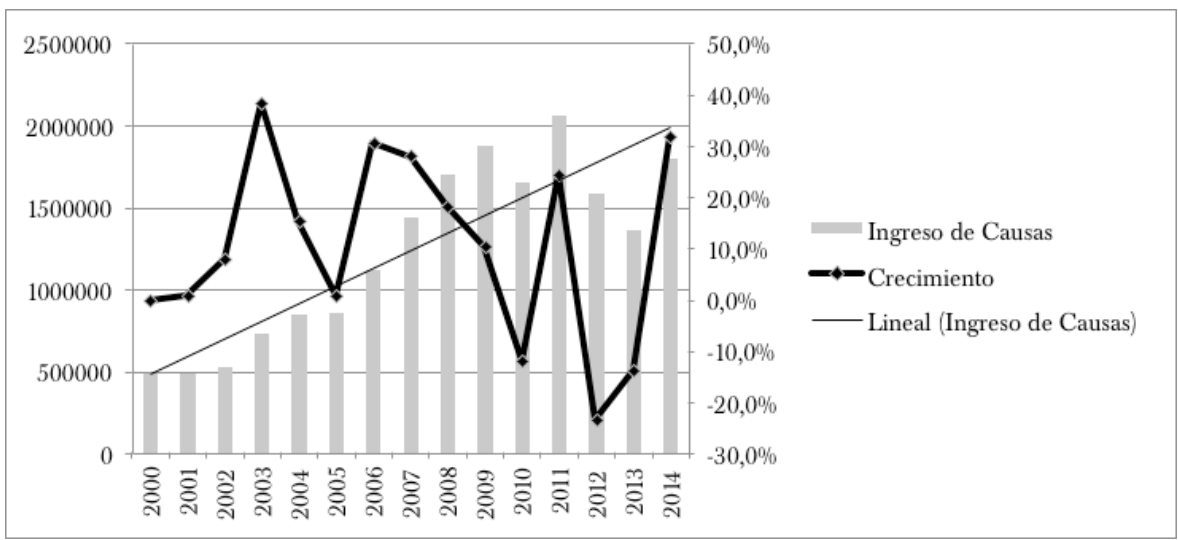

Fuente: Elaborado sobre la base de datos de: EMG Consultores (2012), p. 17; complementado con datos de la Cuenta Pública del Poder Judicial años 2012-2015, disponible en www.poderjudicial.cl [Fecha de consulta: 15 de abril de 2015].

${ }^{73}$ Pontificia Universidad Católica de Valparaíso (2012), p. 13.

${ }^{74}$ Ministerio de Justicia (2012), p. 13.

${ }^{75}$ EMG Consultores (2012), p. 19. 
Si bien todos los años muestran crecimientos positivos (salvo el caso de 2010, producto del terremoto ocurrido en febrero de dicho año) y, en consecuencia, la línea de tendencia es positiva, la tasa de ese crecimiento anual y, por lo mismo, la demanda de justicia civil, es más bien inestable. De esta manera, se observan en el periodo descrito mínimas de $0,9 \%$ (en 2001 y 2005) y una tasa máxima de $38,5 \%$ en $2003^{76-77}$. Luego, si se complementa la información con los datos proporcionados por las cuentas públicas del presidente de la Corte Suprema entre $2010-2014^{78}$, habría una baja en los ingresos entre 2012 y 2013, aun cuando se mantendría una tendencia positiva. Por otra parte, la irregularidad en la demanda de justicia civil continúa si es que se analizan las tasas de crecimiento anual para el periodo completo (gráfico 2).

$\mathrm{El}$ rápido crecimiento del ingreso civil no sería una característica propia del periodo posterior a 2000, sino que hay datos que muestran que este fenómeno también está presente en la década de $1990^{79}$. Rafael Mery, usando datos del INE y de la CAPJ, señala que entre 1973 y 2004 el aumento del ingreso civil fue de un $1.200 \%$, y destaca dos momentos en que este fue particularmente intenso: en $1982 \mathrm{y}$ el periodo posterior a 1990. Respecto de 1982 este autor explica el significativo aumento de causas civiles ingresadas en ese año se produce por la crisis económica y financiera que vivió Chile a partir de 1981 y que se tradujo en un fuerte incremento de juicios ejecutivos y, en general, de juicios de orden económico. Respecto del periodo posterior a 1990, comenzaría allí una tendencia de crecimiento que dura hasta hoy y que atribuye a cinco factores:

a) desarrollo y crecimiento económico;

b) conciencia y democratización ciudadana;

c) explosión demográfica;

d) modernización del Estado y

e) aumento del número de abogados en el país ${ }^{80}$.

Otros autores señalan como causa de este sostenido aumento las deficiencias propias del sistema, que generaría incentivos perversos para abusar de la litigación como estrategia de negociación. Así, la demora en la tramitación de los procedimientos, los costos (económicos y mora-

${ }^{76}$ EMG Consultores (2012), p. 17.

${ }^{77}$ La baja tasa de crecimiento en el caso de 2005 podría deberse a la entrada en vigencia de los Tribunales de Familia, que recibieron algunos asuntos que hasta ese momento conocían los juzgados civiles de Santiago (por ejemplo, separación judicial, nulidades de matrimonio, etc.). El problema es que esto no explica por qué al año siguiente las causas civiles vuelven a crecer un $30 \%$.

${ }^{78}$ Disponible en www.poderjudicial.cl [Fecha de consulta: el 15 de abril de 2015].

${ }^{79}$ García y Castro (2006a), p. 35.

${ }^{80}$ Mery (2006), pp. 99-106. En este mismo sentido, véase García y Leturia (2005), p. 10. 
les) que significaría recurrir al sistema de justicia civil para conseguir el cumplimiento de las obligaciones, y algunos elementos estructurales del sistema (como la creación y dispersión de recursos y acciones; la falta de tasas y costas efectivas; la impredictibilidad de las sentencias y la nula responsabilidad de abogados y jueces), serían condiciones que favorecen el abuso y en consecuencia la sobreutilización de la justicia civil ${ }^{81}$.

En síntesis, los datos muestran con mucha claridad que existe un persistente aumento del número de causas ingresadas a la justicia civil y parecen proyectar que esa expansión debiera continuar en el futuro. Por otra parte, también indican con claridad que la composición de ese ingreso en su mayoría se integraría no por causas contenciosas que den lugar a una verdadera contienda civil, sino a gestiones de cobranza o voluntarias que podrían ser resueltas de manera más sencilla y económica con sistemas administrativos o desjudicializados apropiados ${ }^{82}$.

\section{LA DURACIÓN DE LOS PROCESOS}

Una de las críticas más frecuentes sobre el funcionamiento de la justicia civil en la literatura nacional es la lentitud con que son procesados los casos 30 ingresados al sistema. También en el proyecto de nuevo Código Procesal Civil, cuya discusión se encuentra actualmente suspendida en el Congreso Nacional, se incorporó este problema como uno de los elementos de diagnóstico para la reforma a la justicia civil ${ }^{83}$.

En la doctrina se ha mencionado que la demora o la larga duración de los procesos sería una de las principales causas de la mala percepción que la ciudadanía tiene de la justicia, y donde la reforma a la justicia civil debiera focalizarse. Para algunos, incluso, en la actualidad la duración y dilación innecesarias llegarían al punto de constituir una verdadera denegación de justicia ${ }^{84}$.

La percepción de que los procesos son lentos es sostenida tanto desde trabajos de tipo dogmático como en los escasos estudios de carácter empírico que han sido realizados en el pasado. En este sentido, llama la atención que durante la discusión del actual proceso de reforma no se haya

${ }^{81}$ García y Leturia (2006a), p. 350. Véase también García y Leturia (2006b), pp. 36-37; García y Leturia (2005), pp. 12-13; García y Castro (2006), p. 34.

${ }^{82}$ Para un análisis pormenorizado del sistema de ejecución civil en Chile, de los principales modelos del derecho comparado, así como una propuesta de rediseño, véase: NúNez, Pérez y Vargas (2013).

${ }^{83}$ Véase Ministerio de Justicia (2012), p. 17.

${ }^{84}$ Domínguez (2007), pp. 595-596; NúÑEz (2007), p. 679; Silva y Domínguez (2006), p. 440. 
contado con nuevos y mejores estudios que den cuenta de la realidad de manera más certera y actualizada ${ }^{85}$.

Esta visión sobre la lentitud de la justicia no es un tema nuevo ni particular del actual movimiento de reforma a la justicia civil en nuestro país. Por el contrario, ha sido uno de los motivos históricos de los diversos intentos de reformas o modificaciones al Código de Procedimiento Civil ${ }^{86}$.

En general, es posible observar que en la literatura especializada se denuncia la lentitud de los procesos, se avanzan algunas hipótesis sobre ciertos factores que podrían incidir en el problema, pero no necesariamente suelen hacerse cargo de datos empíricos específicos actualizados, y menos aun representativos desde el punto de vista estadístico, que sustenten dichas afirmaciones y permitan obtener un diagnóstico de mayor calidad respecto a la situación ${ }^{87}$.

Los principales estudios específicos sobre la duración de los procesos en la justicia civil chilena fueron desarrollados por Carlos Cerda en la década de 1980 y principios de la de 1990. De hecho, varios de los otros estudios que se refieren al tema citan el trabajo de este autor para fundamentar sus observaciones ${ }^{88}$.

El primero de ellos fue publicado en 1982 y se denomina La realidad del proceso. El objeto de estudio fueron expedientes judiciales tramitados en procedimientos civiles ordinarios, sumarios y ejecutivos, así como procedimientos penales ordinarios por crimen o simple delito de juzgados de la ciudad de Santiago. En particular, se seleccionaron expedientes de los juzgados civiles: Primero, Segundo, Tercero, Cuarto y Quinto de Santiago ${ }^{89}$.

El criterio de selección de la muestra fue escoger los últimos cien casos terminados en cada uno de estos juzgados, utilizando para ello los libros de ingresos de los juzgados, el prearchivo del despacho de cada juzgado y finalmente, el Archivo Judicial. Bajo dicho criterio, la muestra final en el ámbito civil consistió en trescientos noventa y tres expedientes tramitados bajo procedimiento ordinario, quinientos seis en procedimiento sumario, y cuatrocientos noventa y seis casos en procedimiento ejecutivo. En total, la muestra consistió en 1395 expedientes ${ }^{90}$.

${ }^{85}$ En este sentido, véase: García y Castro (2006), p. 35.

${ }^{86}$ Piedrabuena (1989), p. 649; Tavolari (1992, p. 159; Véase también Otero (2000).

${ }^{87}$ Véase Domínguez (2007); Silva y Domínguez (2006), p. 417; Harasic (2006), pp. 389-390.

${ }^{88}$ Así, por ejemplo, véase García y Leturia (2005), p. 11; VARgas (2006), p. 151; Onfray (1996a), pp. 12-13; VARgas y Correa (1995), pp. 42-43; Onfray (2010), pp. 169170; TAVOlari (1992), p. 159; PeÑa (1993), pp. 378-379; Onfray (1996b), p. 40

${ }^{89}$ Cerda (1982a), pp. 4-5.

${ }^{90}$ Op. cit., p. 5. 
En relación con el procedimiento ordinario, el promedio de duración de la muestra en primera instancia fue de 554,31 días ${ }^{91}$, contados desde el ingreso de la demanda hasta la sentencia definitiva ${ }^{92-93}$.

El promedio de duración en segunda instancia en aquellos casos en que hubo apelación (ciento cuarenta y ocho de los trescientos noventa y tres expedientes) fue de 226,68 días entre su interposición y la sentencia de la Corte ${ }^{94}$. En los casos con apelación el promedio general de duración de ambas instancias fue de 805,59 días (aproximadamente dos años y dos meses), donde la menor duración fue de ciento ochenta y uno y la mayor, de dos mil cuatrocientos ochenta días. De estos, el 27,7\% tuvo una duración entre setecientos treinta y uno a mil noventa y cinco días (entre dos a tres años). Se destaca que 69,6\% de los casos tuvo una duración entre uno a tres años (trescientos sesenta y seis a mil noventa y cinco días) y $18,2 \%$ entre el rango de tres a ocho años (mil novecientos seis a dos mil novecientos veinte días, sin perjuicio de que la mayor observación fue de dos mil cuatrocientos ochenta) $)^{95}$.

TABLA 3

RANGO DE DÍAS EN PROCEDIMIENTO ORDINARIO (1982)

\begin{tabular}{ccc}
\hline Rango de días & Rango en tiempo calendario & \% de la muestra en el rango \\
\hline 241 a 365 & 8 meses a 1 año & $8,8 \%$ \\
366 a 550 & 1 año a 1 año y medio & $20,3 \%$ \\
551 a 730 & 1 año y medio a 2 años & $21,6 \%$ \\
731 a 1095 & 2 a 3 años & $27,7 \%$ \\
1096 a 1460 & 3 a 4 años & $8,8 \%$ \\
1461 a 2109 & 4 a 6 años & $7,4 \%$ \\
2191 a 2920 & 6 a 8 años & $2 \%$ \\
\hline
\end{tabular}

Fuente: CERDA (1982a), pp. 94-95.

En un análisis por materias, en el citado estudio se categorizaron las causas en cuatro grupos según la naturaleza de la acción ordinaria de la que se trataba cada caso ${ }^{96}$. De esta manera, la mayor duración pudo ob-

${ }^{91}$ Cerda (1982a), p. 6.

${ }^{92}$ Sin contar el feriado judicial. Incorporándolo proporcionalmente, el promedio sería de 597,25 días.

${ }^{93}$ Se desconoce si solo se consideraron casos cuyo motivo de término haya sido sentencia definitiva o si se incorporan también otros tipos.

${ }^{94}$ Cerda (1982a), p. 72.

${ }_{95}$ Op. cit., pp. 93-95.

${ }^{96}$ Un problema en este análisis es que no se señala en el estudio la cantidad de casos por materia para este procedimiento. 
servarse en las causas sobre nulidades de contrato con una duración de 739,25 días, y el menor promedio el grupo de causas cuyo objetivo era el "cobro de pesos" con 454,6 días en primera instancia (tabla 4).

TABLA 4

Promedio de díAS DE DURACIÓN EN PRIMERA INSTANCIA

POR MATERIAS EN PROCEDIMIENTO ORDINARIO (1982)

Grupo de causas

Promedio de días duración en primera instancia

\begin{tabular}{ll}
\hline Grupo $1^{97}$ & 566,81 \\
Grupo $2^{98}$ & 454,59 \\
Grupo $3^{99}$ & 688,94 \\
Grupo $4^{100}$ & 738,25 \\
\hline
\end{tabular}

Fuente: CERDA (1982a), pp. 56-57.

En relación con el procedimiento sumario del análisis de la muestra, tomada sobre la base de la misma metodología ${ }^{101}$, arrojó una duración promedio en primera instancia de 192,65 días. El mínimo fue setenta y seis días y la máxima de mil doscientos quince, dando cuenta de una gran variación en términos del rango entre las observaciones. En el análisis por materia, las causas levantadas fueron clasificadas de acuerdo con la 33 naturaleza de la acción ejecutiva en tres categorías. Entre estas, aquellas relacionadas con el arriendo de predios urbanos presentaba el menor promedio de duración en primera instancia y tenía la mayor cantidad de observaciones (tabla 5), lo que puede implicar que respecto este procedimiento utilizar el promedio general no sea una buena aproximación a la tendencia central ${ }^{102-103}$.

\footnotetext{
${ }^{97}$ Aquí se agrupó la casi totalidad de los asuntos medidos, a saber: alimentos entre mayores; cumplimiento de contrato; resolución de contrato; indemnización de perjuicios; otras nulidades (de testamento, de inscripción, de expropiación, etc.); petición de herencia; reforma de testamento; rescisión por lesión enorme; acción redhibitoria; acción reivindicatoria; impugnación de paternidad; etcétera.

${ }^{98}$ Este grupo lo componían las acciones cuyo objetivo es el "cobro de pesos".

${ }^{99}$ En el tercer conjunto se agruparon las acciones que persiguen la "declaración" de un derecho.

${ }^{100}$ Esta categoría se componía de las "nulidades de contrato".

${ }^{101}$ Quinientos cinco expedientes efectivamente contabilizados y uno excluido por error en la ficha utilizada en el levantamiento de información.

${ }^{102}$ Cerda (1982b), p. 43.

${ }^{103}$ La cantidad de casos utilizados para el análisis por materia es menor al total de observaciones bajo procedimiento sumario. Según el citado estudio, esto es por error en las fichas de levantamiento de información. Véase op. cit., p. 43
} 
TABLA 5

Promedio de díAS DE DURACIÓN EN PRIMERA INSTANCIA POR MATERIAS EN PROCEDIMIENTO SUMARIO (1982)

\begin{tabular}{ccc}
\hline Grupo de casos por materia & Observaciones & $\begin{array}{c}\text { Promedio de días de duración } \\
\text { en primera instancia }\end{array}$ \\
\hline Grupo $1^{104}$ & 238 & 174,16 \\
Grupo 2 & 214 & 203,90 \\
Grupo 3 & 45 & 238,69 \\
\hline
\end{tabular}

Fuente: CERDA (1982b), p. 44

En relación con la segunda instancia, el promedio de duración en general en aquellos casos que llegaron a dicha etapa (doscientos nueve expedientes) fue de 124,34 días. Entre ambas instancias el promedio general fue de 324,78 días. De estos últimos, la mayor proporción se encontraba en el rango entre doscientos cuarenta y uno a trescientos sesenta y cinco días (ocho meses a un año) (tabla 6).

TABLA 6

DURACIÓN POR RANGO DE DÍAS EN PROCEDIMIENTO SUMARIO (1982)

Rango Porcentaje

Uno a ciento cincuenta días

(hasta cinco meses)

$12,4 \%$

Ciento cincuenta y uno a doscientos cuarenta días

(de cinco a ocho meses)

$21,5 \%$

Doscientos cuarenta y uno a trescientos sesenta y cinco días

(de ocho meses a un año)

$35,4 \%$

Trescientos sesenta y seis a quinientos cincuenta días

(de un año a un año y medio)

$23 \%$

Quinientos cincuenta y uno a setecientos treinta días

(de un año y medio a dos años)

$4,3 \%$

Setecientos treinta y uno a mil novecientos cinco días

(de dos a tres años)

$1,9 \%$

Mil noventa y seis y mil cuatrocientos sesenta

(de tres a cuatro años, la máxima fue de mil doscientos quince días) $\quad$ 1,4\%

Fuente: CERDA (1982b), pp. 76-77.

${ }^{104}$ Asuntos relativos a arrendamiento de previos urbanos (desahucio, terminación por falta de pago de la renta, terminación por extinción del derecho del arrendador, reconvenciones de pago, fijación de renta, restitución de la cosa arrendada, etcétera).

${ }^{105}$ Comodato precario.

${ }^{106}$ Otras cuestiones que por el ministerio de la ley o su naturaleza requieren de tramitación sumaria (art. 680 del Código de Procedimiento Civil), tales como: cobro de honorarios, objeciones en una rendición de cuentas, servidumbres, pagos, restituciones, etcétera. 
Respecto a la duración del procedimiento ejecutivo esta investigación arroja como resultado, sobre una muestra de cuatrocientos noventa y cinco expedientes ${ }^{107}$ seleccionados, un promedio de 182,89 días en primera instancia desde el ingreso de la demanda a la dictación de la sentencia definitiva ${ }^{108}$.

En cuanto a aquellas causas en que hubo segunda instancia (noventa y tres expedientes), el promedio de duración de esta última fue de 199,4 días. Tomando en consideración estos casos, en ambas instancias el promedio de duración fue de 476,6 días. De estas últimas, llama la atención que el $51,6 \%$ tuvo una duración entre doscientos cuarenta y uno a quinientos cincuenta días (ocho meses a un año y seis meses) (tabla 7) ${ }^{109}$.

\section{TABLA 7}

DURACIÓN POR RANGO DE DÍAS EN PROCEDIMIENTO EJECUTIVO (1982)

\begin{tabular}{|c|c|}
\hline Rango & Porcentaje \\
\hline $\begin{array}{l}\text { Uno a ciento cincuenta días } \\
\text { (hasta cinco meses) }\end{array}$ & $3,2 \%$ \\
\hline $\begin{array}{l}\text { Ciento cincuenta y uno a doscientos cuarenta días } \\
\text { (de cinco a ocho meses) }\end{array}$ & $17,2 \%$ \\
\hline $\begin{array}{l}\text { Doscientos cuarenta y uno a trescientos sesenta y cinco días } \\
\text { (de ocho meses a un año) }\end{array}$ & $20,4 \%$ \\
\hline $\begin{array}{l}\text { Trescientos sesenta y seis a quinientos cincuenta días } \\
\text { (de un año a un año y medio) }\end{array}$ & $31,2 \%$ \\
\hline $\begin{array}{l}\text { Quinientos cincuenta y uno a setecientos treinta días } \\
\text { (de un año y medio a dos años) }\end{array}$ & $12,9 \%$ \\
\hline $\begin{array}{l}\text { Setecientos treinta y uno a mil novecientos cinco días } \\
\text { (de dos a tres años) }\end{array}$ & $9,7 \%$ \\
\hline $\begin{array}{l}\text { Mil noventa y seis y mil cuatrocientos sesenta } \\
\text { (de tres a cuatro años) }\end{array}$ & $1,1 \%$ \\
\hline $\begin{array}{l}\text { Mil cuatrocientos sesenta y uno a dos mil ciento noventa } \\
\text { (de cuatro a seis años) }\end{array}$ & $4,3 \%$ \\
\hline
\end{tabular}

Fuente: CERDA (1982c), pp. 71-72.

De acuerdo con la materia o naturaleza del título ejecutivo que fundamenta la acción, la duración de las causas de mayor frecuencia fueron las letras de cambio y las sentencias de juicio de arriendo, con promedios

${ }^{107}$ La muestra original era de cuatrocientos noventa y seis casos, la exclusión según se reporta se debe a un error en el fichero utilizado para el levantamiento de información. Véase CERDA (1982c), p. 1.

${ }^{108} \mathrm{Al}$ igual que con los otros procedimientos, se desconoce si también se consideraron causas con otros motivos de término. Ibid.

${ }^{109}$ CERDA (1982c), pp. 71-72. 
de 182,1 y 132,4 días respectivamente ${ }^{110}$. En aquellas causas con ambas instancias, las letras demoraron en promedio 472,1 días y las escrituras públicas 578,1 días (tabla 8).

TABLA 8

Promedio de duración EN días PROCEDimiento EjeCutivo POR TIPO DE TÍtULO EJECUTIVO EN PRIMERA Y AMBAS INSTANCIAS (1982)

Primera instancia Frecuencia Duración Frecuencia Duración

Ambas instancias

Tipo de título ejecutivo

$\begin{array}{lrrrc}\text { Letra } & 189 & 182,1 & 29 & 472,1 \\ \text { Cheque } & 41 & 155,6 & 3 & 239,7 \\ \text { Pagaré } & 8 & 137,1 & - & - \\ \text { Escritura pública } & 71 & 253,6 & 27 & 578,1 \\ \text { Confesión de deuda } & 40 & 180,6 & 9 & 329,1 \\ \text { Avenimiento } & 2 & 174 & - & - \\ \text { Sentencia en juicio de arrendamiento } & & & & \\ \text { (terminación y restitución) } & 91 & 132,4 & 10 & 479,8 \\ \text { Sentencia en juicio de comodato precario } & 7 & 187,4 & 2 & 379,5 \\ \text { Sentencia en cobro de honorarios } & 6 & 95,3 & 1 & 396 \\ \text { Otras sentencias } & 17 & 199,2 & 7 & 360,1 \\ \text { Otros títulos } & 13 & 239,9 & 3 & 514,7 \\ \text { Obligaciones de hacer } & 10 & 262,6 & 2 & 660,5 \\ \text { Total } & 495 & 182,9 & 93 & 476,6 \\ \end{array}$

Fuente: CERDA (1982c,) pp. 37-38.

Este mismo autor publicó, entre 1992 y 1993, dos estudios específicos referidos a la duración del procedimiento ordinario ${ }^{111}$ y sumario ${ }^{112}$.

El primero fue realizado sobre una muestra de seiscientos cincuenta y ocho expedientes escogidos entre ocho juzgados civiles de la capital (de los treinta existentes a la época), consistentes en casos tramitados bajo procedimiento ordinario que se encontraban terminados en una, dos o ambas instancias ${ }^{113}$.

En aquellos casos que presentaban ambas instancias (trescientos setenta y tres expedientes) el promedio de duración fue de mil nueve días. La mínima duración observada fue de ciento veintidós y la máxima de cuatro mil trescientos veinticinco días. A diferencia del primero de los estudios sobre procedimiento ordinario, la mayoría de causas $(20,4 \%)$ se

${ }^{110}$ Cerda (1982c), pp. 37-38.

111 Cerda (1992).

112 Cerda (1993).

${ }^{113}$ Cerda (1992), p. 1. La muestra se obtuvo escogiendo las últimas causas terminadas en cada uno de los ocho tribunales hasta el 31 de diciembre de 1991 y con un máximo de cien, excluyendo aquellas relacionadas con nulidad de matrimonio. 
encontraba en el rango entre trescientos sesenta y seis a quinientos cincuenta días (un año a un año y medio), aunque destaca, también, que una gran proporción, el 19,3\%, tuvo una duración entre setecientos treinta y uno a mil noventa y cinco (dos a tres años). Luego, el 15\% de doscientos cuarenta y uno a trescientos sesenta y cinco y el 14,4\% en el rango de quinientos cincuenta y uno a setecientos treinta días. Por otra parte, el $23,9 \%$ tuvo una duración entre mil noventa y seis a cuatro mil trescientos veinticinco días (la máxima) y tan solo el 6,8\% tuvo una duración entre ciento veintidós a doscientos cuarenta días ${ }^{114}$.

TABLA 9

DURACIÓN POR RANGO DE DÍAS EN PROCEDIMIENTO EJECUTIVO (1992)

\begin{tabular}{ccc}
\hline Rango de días & Rango en tiempo calendario & \% de la muestra en el rango \\
\hline 122 a 240 & Hasta ocho meses & $6,8 \%$ \\
241 a 365 & Ocho meses a un año & $15 \%$ \\
366 a 550 & Un año a un año y medio & $20,4 \%$ \\
551 a 730 & Un año y medio a dos años & $14,4 \%$ \\
731 a 1095 & Dos a tres años & $19,3 \%$ \\
1096 a 1460 & Tres a cuatro años & $10,6 \%$ \\
1461 a 2190 & Cuatro a seis años & $10,6 \%$ \\
Sobre 2191 & Sobre seis años & $2,7 \%$ \\
\hline
\end{tabular}

Fuente: CERDA (1992), pp. 1-2.

De la totalidad de casos seleccionados (seiscientos cincuenta y tres expedientes), la duración promedio en primera instancia fue de seiscientos doce días, contados desde que la demanda era proveída hasta la sentencia definitiva (en comparación a los 554,3 del estudio de 1982) ${ }^{115}$. En segunda instancia (respecto de los trescientos setenta y tres que llegaron a dicha fase), la duración promedio fue de trescientos cincuenta y nueve días (en el estudio de 1982 fueron 226,7 días). La mínima duración fue de siete días y la máxima de cuatro años y cuatro meses. El 40\% de estas causas se encontraba en el rango entre nueve y doce meses, $11 \%$ entre seis y siete meses, y el 7\% de un mes y medio. El 42\% restante tomaba entre catorce meses y cuatro años ${ }^{116}$.

En este estudio se destaca como un elemento importante a considerar la entrada en vigencia de la ley $\mathrm{N}^{\mathrm{O}}$ 18.705. Esta disposición introdujo varias modificaciones al Código de Procedimiento Civil que buscaron incidir

${ }^{114}$ CERda (1992), p. 2.

${ }^{115} \mathrm{Al}$ igual que en el estudio anterior, se desconoce si se consideraron causas con otros motivos de término.

${ }^{116}$ CERda (1992), p. 19. 
directamente en la duración del procedimiento ordinario. De esta manera, se señala que aquellas causas iniciadas con anterioridad a la entrada en vigencia de la ley tenían una demora promedio en ambas instancias de novecientos setenta y tres días (ciento sesenta y nueve expedientes) y que, en cambio, en aquellas ingresadas con posterioridad el tiempo de tramitación era de quinientos días en promedio ${ }^{117}$. En este mismo sentido, la duración de la primera instancia, en aquellos casos terminados antes de la entrada en vigencia, el promedio era de seiscientos sesenta y nueve días (doscientos treinta de los seiscientos cincuenta y tres expedientes), y en aquellos que comenzaron a tramitarse con posterioridad, era de trescientos treinta y ocho días (ciento setenta y uno de los seiscientos cincuenta y tres $)^{118}$. Por último, respecto de la segunda instancia, aquellas causas terminadas antes de la entrada en vigencia, tomaban en promedio trescientos cincuenta y un días y aquellas que se iniciaron con posterioridad ciento setenta y un días ${ }^{119}$.

Estos resultados implicarían, entonces, que esta reforma legal habría tenido un impacto positivo en términos de la reducción de los tiempos de duración del procedimiento ordinario. Sin embargo, creemos que estos resultados deben ser interpretados con mucha precaución por dos motivos.

En primer lugar, de la experiencia en el trabajo en reformas a la justicia en diversos países de la región latinoamericana en instituciones como el CEJA, donde ambos autores de este documento han ejercido como investigadores, se entiende que estos procesos de reforma son complejos y requieren para que sean exitosos de más que simples modificaciones de normas procesales. Por el contrario, demandan una visión de políticas públicas que impacte en el funcionamiento práctico de los sistemas judiciales y de la cultura organizacional de sus instituciones ${ }^{120}$.

En segundo lugar, estos resultados deben ser matizados dadas ciertas limitaciones metodológicas presentes en el estudio. En particular, aquí puede haber lo que se denomina sesgo de selección. Si se toma en consideración que la muestra de total de seiscientos cincuenta y ocho expedientes fue levantada a mediados de 1991, a la vez que la citada ley $\mathrm{N}^{\mathrm{O}} 18.705$ entró en vigencia en junio de 1988, y dado que solo se levantaron causas terminadas, es lógico, entonces, que aquellas causas seleccionadas correspondientes a las iniciadas con posterioridad a la entrada la vigencia no podrían haber tenido una duración entre ambas instancias mayor a tres años. Es razonable pensar que el promedio en primera instancia, segunda

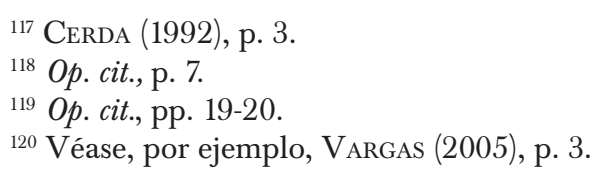


instancia y en ambas en conjunto sería menor al promedio de duración de aquellas causas iniciadas antes de la entrada en vigencia de la ley $\mathrm{N}^{\mathrm{O}}$ 18.705. Por el contrario, para evaluar de mejor manera el impacto de esta reforma, debió haberse modificado la manera en que se tomó la muestra y probablemente haber repetido el estudio algunos años después.

El estudio sobre el procedimiento sumario de este mismo autor publicado en 1993 fue realizado sobre una muestra de ochocientos cinco expedientes seleccionados entre ocho juzgados civiles de Santiago. La muestra se obtuvo mediante una selección de causas terminadas bajo procedimiento sumario distribuidas entre estos juzgados ${ }^{121}$.

En aquellos ciento tres expedientes que tuvieron ambas instancias, la duración media fue de quinientos trece días (en comparación, en el estudio de 1982 el mismo valor fue 324,78 días). Por otro lado, la mínima fue de setenta y nueve días y la máxima mil seiscientos veintitrés. La mayoría se encontraba en el rango entre trescientos sesenta y seis a quinientos cincuenta días (tabla 10). En comparación, en el estudio de 1982 en esta categoría se encontraba el 13,6\% de los casos y la mayoría se ubicaban en el rango entre doscientos cuarenta y uno a trescientos sesenta y cinco días ${ }^{122}$.

TABLA 10

DURACIÓN POR RANGO DE DÍAS EN PROCEDIMIENTO SUMARIO (1993)

\begin{tabular}{|c|c|}
\hline Rango & Porcentaje \\
\hline $\begin{array}{l}\text { Uno a ciento cincuenta días } \\
\text { (hasta cinco meses) }\end{array}$ & $4,9 \%$ \\
\hline $\begin{array}{l}\text { Ciento cincuenta y uno a doscientos cuarenta días } \\
\text { (de cinco a ocho meses) }\end{array}$ & $18,4 \%$ \\
\hline $\begin{array}{l}\text { Doscientos cuarenta y uno a trescientos sesenta y cinco días } \\
\text { (de ocho meses a un año) }\end{array}$ & $13,6 \%$ \\
\hline $\begin{array}{l}\text { Trescientos sesenta y seis a quinientos cincuenta días } \\
\text { (de un año a un año y medio) }\end{array}$ & $25,2 \%$ \\
\hline $\begin{array}{l}\text { Quinientos cincuenta y uno a setecientos treinta días } \\
\text { (de un año y medio a dos años) }\end{array}$ & $18,4 \%$ \\
\hline $\begin{array}{l}\text { Setecientos treinta y uno a mil novecientos cinco días } \\
\text { (de dos a tres años) }\end{array}$ & $12,6 \%$ \\
\hline $\begin{array}{l}\text { Mil noventa y seis a mil cuatrocientos sesenta } \\
\text { (de tres a cuatro años) }\end{array}$ & $4,9 \%$ \\
\hline $\begin{array}{l}\text { Mil cuatrocientos sesenta y uno a dos mil ciento noventa } \\
\text { (de cuatro a seis años) }\end{array}$ & $1,9 \%$ \\
\hline
\end{tabular}

Fuente: CERDA (1993), pp. 1-2.

${ }^{121}$ Cerda (1993), p. 1.

${ }^{122}$ Op. cit., pp. 1-2. 
De la totalidad de expedientes (ochocientos cinco), la duración media en primera instancia fue de doscientos sesenta y tres días. Por materias agrupadas en categorías, aquellas causas relativas a temas de arriendos (seiscientos catorce expedientes) tuvieron un promedio de doscientos treinta y tres días, aquellas sobre comodatos precarios (ciento trece expedientes) doscientos setenta y nueve días, los cobros de honorarios veintiséis días (cuatrocientos treinta y nueve casos), y por último, la categoría "otros" (compuesto por cincuenta y dos expedientes) demoró en promedio cuatrocientos ochenta y nueve días en primera instancia ${ }^{123}$.

De los ciento tres casos donde hubo apelación, la segunda instancia duró en promedio doscientos diez días. La mayor duración fue de mil seiscientos veintitrés días y la más corta de setenta y nueve. El 18,4\% tuvo una duración entre cinco y ocho meses, y otro 18,4\% entre un año y medio y dos años ${ }^{124}$.

Ambos estudios realizados por Carlos Cerda en las décadas de 1980 y 1990 tienen importantes limitaciones metodológicas y, en particular, respecto a la validez externa de sus resultados ${ }^{125}$. En primer lugar, hay una limitación esencial que impide la generalización de los datos utilizados como fuente para la duración de los procedimientos en la jurisdicción de Santiago y menos en el ámbito nacional (tampoco creemos que el autor así lo pretenda). De esta manera, si en el estudio de 1982 se seleccionaron cuatro a cinco de los diez juzgados existentes a la época (dependiendo el tipo de procedimiento), en el estudio de 1992 fueron seleccionados ocho de los treinta que había en funcionamiento en ese momento. De las publicaciones de estos estudios no queda claro el motivo de por qué se acotó a esta cantidad de tribunales ni tampoco si fueron seleccionados al azar, lo que podría atenuar este problema metodológico.

En segundo lugar, de los tribunales sobre los cuales se levantó la muestra final de casos a ser analizados, solo señala la cantidad que fueron elegidos, no así el método específico que se usó para ello. Por ejemplo, no es claro por qué en el estudio de 1982 los casos del Primer Juzgado Civil representaban el 67,7\% de la muestra, muy por encima de la participación de los demás juzgados, lo que podría implicar un problema de representatividad importante ${ }^{126}$.

${ }^{123}$ Cerda (1993), p. 10.

${ }^{124}$ Op. cit., p. 16

${ }^{125}$ Es decir, de aquellas que impiden la generalización de los datos.

${ }^{126}$ En relación con el procedimiento ordinario el análisis se hizo sobre la base de trescientos ochenta y siete de trescientos noventa y tres expedientes seleccionados inicialmente, doscientos sesenta y dos del Primer Juzgado Civil de Santiago, setenta y siete del Segundo Juzgado Civil de Santiago, treinta y dos del Tercer Juzgado Civil de Santiago y dieciséis del Cuarto Juzgado Civil de Santiago. De acuerdo con el estudio, el motivo de 
En tercer lugar, del universo de casos disponibles se consideraron solo aquellos que se encontraban terminados, pero no se explicita el tipo de término que estos tuvieron (aunque de los datos pareciera que solo se trata de los afinados mediante sentencia definitiva). El problema de lo anterior es que sobre la base de datos más recientes sabemos que las sentencias definitivas constituyen un porcentaje relativamente bajo de los motivos de término. Esta situación también constituye un importante sesgo de selección que impide generalizar las conclusiones a las que llegan estos estudios y, por lo mismo, limitan su utilidad como datos esenciales para la formulación de políticas públicas judiciales.

En consecuencia, estos estudios tienen limitaciones metodológicas que afectan la representatividad de la muestra, además de problemas en los criterios de selección de las causas que la integran y los juzgados que fueron incorporados a la medición. No obstante, son los principales estudios empíricos que se han hecho sobre la materia en el país y han sido citados y utilizados por la doctrina nacional en reiteradas ocasiones. Además, de todas maneras permiten tener una aproximación, aunque general, a los órdenes de magnitud de los tiempos procesales y de algunas de las etapas de los juicios civiles.

Algunos años después, otro estudio fue realizado por estudiantes de Derecho de la Pontificia Universidad Católica de Chile. Esta investigación consistió en el análisis de ciento ochenta y seis causas archivadas entre 1998 y 2002, seleccionadas aleatoriamente de trece juzgados civiles de Santiago. De la muestra, el promedio de la duración fue de 785,2 días para el procedimiento ejecutivo; 2009,4 días para el procedimiento ordinario; 707,4 días para el procedimiento sumario; y el promedio general era de 1.066 días $^{127-128}$.

El último estudio de tipo empírico de relevancia que ha sido posible identificar fue encargado por el Ministerio de Justicia al CEJA y publicado en 2011. Este trabajo, si bien no tuvo como objeto principal la medición de la duración, sí contiene datos importantes sobre este aspecto en procedimientos ordinarios, sumarios y ejecutivos.

De acuerdo con este estudio, realizado sobre la base de datos de 2009, la duración promedio del procedimiento ordinario fue de 217,7 días ${ }^{129}$. En

la depuración de la muestra fueron errores o inexactitudes en las fichas utilizadas para el levantamiento de información. Véase CERDA (1982a), p. 56.

${ }^{127}$ Citado en García y Leturia (2006a), p. 351.

${ }^{128} \mathrm{Si}$ bien no ha sido posible encontrar el estudio, de acuerdo con el artículo desde donde fue obtenida esta información, este estudio habría tomado en consideración la duración de causas terminadas, ya sea por sentencia definitiva o algún equivalente jurisdiccional, o que fueron archivadas por abandono de procedimiento.

${ }^{129}$ Según la publicación, las causas tramitadas bajo procedimiento ordinario sería el 1,46\%. Véase Centro de Estudios de Justicia de las Américas (2011), p. 17. 
relación con aquellos casos terminados por sentencia definitiva (que pudo haber sido de primera o segunda instancia), estos tenían un promedio de duración de ochocientos veintiún días (un poco más de dos años), pero con una alta dispersión de datos (desde un mínimo de veintidós a un máximo de más de trece mil días) ${ }^{130}$.

Una cuestión interesante que aparece reflejada, es que el promedio general de duración se ve influenciado por aquellas causas terminadas de forma anticipada, por no haber sido tramitadas por las partes y que, por lo mismo, son consideradas como terminadas de manera temprana. Así, por ejemplo, aquellas terminadas y declaradas como "téngase por no presentada la demanda" o "demanda sin movimiento" y que representan en conjunto aproximado el $75 \%$ de los términos en procedimiento ordinario, tienen promedios de duración de 55,3 y ciento diecinueve días respectivamente (tabla 11) ${ }^{131}$.

TABLA 11

DURACIÓN (EN DÍAS) POR TIPO DE TÉRMINO EN PROCEDIMIENTO ORDINARIO

$\begin{array}{cccccc}\text { Tipo de término } & \begin{array}{c}\text { Número } \\ \text { de casos }\end{array} & \% \text { del total } & \text { Mínimo } & \text { Promedio } & \text { Máximo } \\ \text { terminados } & \text { términos } & \text { duración } & \text { duración } & \text { duración }\end{array}$

Téngase por no presentada

la demanda

5.571

3.632

Demanda sin movimiento

Sentencia definitiva

Total
1.630

12.278

$\begin{array}{rr}45,37 \% & 2 \\ 29,58 \% & 32 \\ 13,28 \% & 22 \\ 100 \% & 2\end{array}$

55,3

119,0

821,0

217,7
2.881

24.201

Fuente: Centro de Estudios de Justicia de las Américas (2011).

Por otro lado, el promedio de duración general de las causas tramitadas bajo procedimiento sumario ${ }^{132}$ fue de doscientos veinticuatro días. Si se toman en consideración los tipos de términos de estas causas, las finalizadas mediante sentencia definitiva tuvieron una duración promedio de 226,7 días, y en los casos terminados con un "téngase por no presentada la demanda" un promedio de 78,9 días (tabla 12) ${ }^{133}$.

${ }^{130}$ De acuerdo con lo que se señala en este estudio, de las causas que tuvieron apelación su duración, entre el ingreso del recurso hasta la sentencia de segunda instancia, transcurrían en promedio novecientos setenta días. Véase CENTRo de Estudios DE Justicia DE LAS AMÉRICAS (2011), p. 46

${ }^{131}$ Op. cit., p. 23.

${ }^{132}$ Que representarían el 0,98\% del total de causas terminadas en los tribunales civiles de Santiago.

${ }^{133}$ Centro de Estudios de Justicia de las Américas (2011), p. 24. 
La gran divergencia entre los promedios de duración frente al procedimiento ordinario es que, a diferencia de lo que ocurría con este último, en el procedimiento sumario el tipo de término más frecuente sería la sentencia definitiva con un $65,7 \%,{ }^{134}$ y le seguirían los casos finalizados con un "téngase por no presentada la demanda" con un 10,7\% y las "demandas sin movimiento" con un 6,7\% (tabla 10$)^{135}$.

TABLA 12

DURACIÓN (EN DÍAS) POR TIPO DE TÉRMINO EN PROCEDIMIENTO SUMARIO

\begin{tabular}{lccccc}
\hline Tipo de término & $\begin{array}{c}\text { Número } \\
\text { de casos } \\
\text { terminados }\end{array}$ & $\begin{array}{c}\% \text { del total } \\
\text { de }\end{array}$ & $\begin{array}{c}\text { Mínimo } \\
\text { de } \\
\text { duración } \\
\text { (en días) }\end{array}$ & $\begin{array}{c}\text { Promedio } \\
\text { de } \\
\text { duración } \\
\text { (en días) }\end{array}$ & $\begin{array}{c}\text { Máximo } \\
\text { de } \\
\text { duración } \\
\text { (en días) }\end{array}$ \\
\hline $\begin{array}{l}\text { Sentencia definitiva } \\
\text { Téngase por no presentada }\end{array}$ & 5.184 & $65,72 \%$ & 12 & 226,7 & 4.516 \\
$\begin{array}{l}\text { la demanda } \\
\begin{array}{l}\text { Demanda sin movimiento } \\
\text { Total }\end{array}\end{array}$ & 543 & $10,69 \%$ & 2 & 78,9 & 9.510 \\
& 7.888 & $6,67 \%$ & 43 & 166,5 & 643 \\
& $100 \%$ & 2 & 223,9 & 9.510 \\
\hline
\end{tabular}

Fuente: Centro de Estudios de Justicia de las Américas (2011).

Por último, las causas terminadas y tramitadas bajo el procedimiento ejecutivo representaban la gran mayoría en la base de datos utilizada $(96,45 \%)^{136}$. A diferencia de lo que ocurría con el ordinario y, en particular, respecto del sumario, el principal tipo de término en el procedimiento ejecutivo es el "téngase por no presentada la demanda" con un $82,8 \%$, seguido de "demanda sin movimiento" con un 10\% y "No da curso a la demanda" con $3,4 \%$. Por su parte, las causas terminadas con sentencia definitiva solo alcanzan al $0,4 \%$ (tabla 13$)^{137}$, cifras que refuerzan también

${ }^{134}$ Respecto de las diferencias con el mismo tipo de término en el procedimiento ordinario, los autores del estudio señalan que algunas explicaciones podrían estar ligadas a su estructura, que contempla una audiencia de contestación (sin los trámites de réplica y dúplica) y plazos más breves. Otro tanto podría atribuirse a la conducta de los litigantes, quienes viendo acceso a resultados ciertos en corto tiempo mantendrían vivo el proceso hasta su finalización. Véase Centro de Estudios de Justicia de las Américas (2011), p. 25.

${ }^{135}$ Centro de Estudios de Justicia de las Américas (2011), p. 24

${ }^{136}$ Op. cit., p. 17

${ }^{137}$ De acuerdo con los autores de este estudio, el principal motivo de la alta incidencia de estas causas "no tramitadas" tiene relación con la normativa del Servicio de Impuestos Internos y los castigos que impone a los créditos incobrables. En virtud de esta, señalan, uno de los requisitos para admitir la deducción de castigos es haber agotado prudencialmente los medios de cobro por parte del acreedor, lo que se puede hacer de diversas formas (llamadas telefónicas, cartas certificadas, entre otras), pero si se trata de deudas superiores a 
el argumento de Raúl Núñez, Álvaro Pérez y Macarena Vargas en términos del uso de los tribunales civiles para el cumplimiento de trámites necesarios para cobranzas, y que veíamos en el acápite anterior.

La diversidad en los tipos de término también se refleja en las diferencias en los tiempos de término para cada uno de ellos. De esta manera, si bien el promedio general es de sesenta y dos días, esto contrasta con la duración en aquellas causas terminadas por pago del crédito y sentencia definitiva cuyas duraciones fueron 360,6 y 427,2 respectivamente (tabla $13)^{138}$. Esto quiere decir que, en los casos que son tramitados y procesados por el sistema hasta un tipo de término de mayor calidad, los tiempos de duración son bastante más altos que respecto de los que son presentados, pero luego no continuados por las partes. Esto, sin duda distorsiona cualquier intento de medición de la duración del procedimiento propiamente tal.

TABLA 13

DURACIÓN (EN DÍAS) POR TIPO DE TÉRMINO EN PROCEDIMIENTO EJECUTIVO

\begin{tabular}{lccccc}
\hline Tipo de término & $\begin{array}{c}\text { Número } \\
\text { de casos } \\
\text { terminados }\end{array}$ & $\begin{array}{c}\% \text { del total } \\
\text { de } \\
\text { términos }\end{array}$ & $\begin{array}{c}\text { Mínimo } \\
\text { de } \\
\text { duración } \\
\text { (en días) }\end{array}$ & $\begin{array}{c}\text { Promedio } \\
\text { deración } \\
\text { (en días) }\end{array}$ & $\begin{array}{c}\text { Máximo } \\
\text { de } \\
\text { duración } \\
\text { (en días) }\end{array}$ \\
\hline Téngase por no presentada & & & & & \\
la demanda & 644.166 & $82,778 \%$ & 1 & 45,4 & 5.592 \\
Demanda sin movimiento & 77.913 & $10,012 \%$ & 31 & 128,6 & 707 \\
Pago del crédito & 9.906 & $1,273 \%$ & 7 & 360,6 & 9.540 \\
Sentencia definitiva & 2.828 & $0,363 \%$ & 16 & 427,2 & 5.446 \\
Total & 778.181 & $100 \%$ & 0 & 61,8 & 20.517 \\
\hline
\end{tabular}

Fuente: Centro de Estudios de Justicia de las AmÉricas (2011).

En relación con el procedimiento ejecutivo, otro estudio fue encargado por el Ministerio de Justicia a propósito del diseño de un modelo de oficial de ejecución. Este estudio efectuado por la Pontificia Universidad Católica de Valparaíso da cuenta de los tiempos de duración en causas terminadas según el tipo de conclusión en Santiago y que son coincidentes con aquellos del Estudio del CEJA ${ }^{139}$.

50 UF se exige "haber requerido judicialmente al deudor y haber realizado las actuaciones procesales propias y razonables del procedimiento judicial de que se trate". CENTRO DE Estudios de Justicia de las Américas (2011), p. 28.

${ }^{138}$ Op. cit., p. 30.

${ }^{139}$ Pontificia Universidad Católica de Valparaíso (2012). 


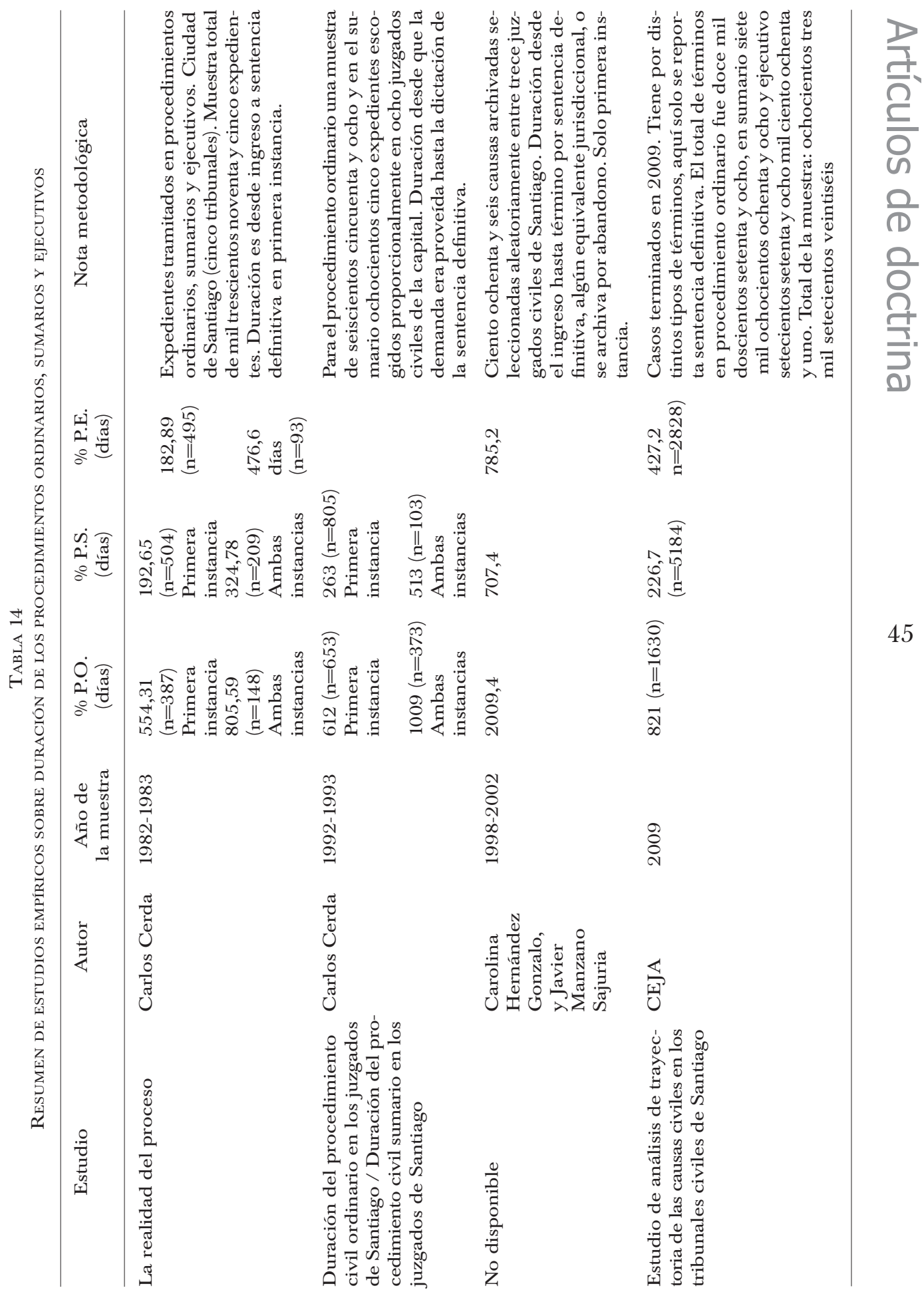


A pesar de las diferencias metodológicas y la imposibilidad de medir la relación entre los datos, de la sola lectura de los resultados puede verse cierta conformidad entre la duración de ambas instancias en el primer estudio de Carlos Cerda de la década de 1980 y del estudio del CEJA realizado sobre causas terminadas en 2009, al menos si se consideran solo aquellos casos terminados por sentencia definitiva (tabla 14).

Además de estos estudios empíricos disponibles, todavía es posible encontrar otras menciones a la duración de los procedimientos en la literatura existente, aunque no queda absolutamente claro que tipos de datos o metodologías son utilizadas para sus estimaciones. En este sentido, Davor Harasic señalaba que el procedimiento declarativo ordinario no duraba menos de dos años en primera instancia; que la Corte de Apelaciones de Santiago tiene un retraso que hace que las apelaciones de sentencias definitivas se vean en un periodo de entre tres y cuatro años desde el momento que ingresan; y que en la Corte Suprema, las casaciones no son conocidas antes de dos a tres años ${ }^{140}$. En este sentido, para este autor era posible contar con una sentencia definitiva ejecutoriada a los siete años ${ }^{141}$. A mayor abundamiento, en 2003 otra estimación indicaba que la duración de la totalidad de casos tramitados en primera instancia en los juzgados civiles de Santiago fue un promedio aproximado de trescientos días ${ }^{142}$.

Más allá de lo anterior, otros tipos de estudios también han buscado medir la duración del procedimiento civil basado en otras metodologías y, en general, de manera de tener un punto de comparación entre países. Por ejemplo, el Banco Mundial lo ha considerado sobre la base del tiempo que toma hacer valer un contrato, donde Chile aparece con una duración de trescientos cinco días, y el estudio de Lex Mundi Project sobre la base de la duración total de un proceso por desalojo de un arrendatario que no paga y en otro para el cobro de un cheque, ubicaba a Chile en doscientos cuarenta y doscientos días respectivamente ${ }^{143}$. En 2015, el mismo informe del Banco Mundial, denominado Doing Business, señalaba que el tiempo para hacer efectivo un contrato en Chile era de cuatrocientos ochenta días (donde el promedio en la región de América Latina eran setecientos ocho días $)^{144}$.

En síntesis, podemos decir que una lectura conjunta de los estudios que han pretendido medir la duración de los procesos civiles permite extraer algunas conclusiones muy generales que parecen interesantes. Por ejemplo,

${ }^{140}$ Harasic (2006), p. 390.

${ }^{141}$ Op. cit., pp. 389-390.

${ }^{142}$ Citado en García y Leturia (2005), p. 12.

${ }^{143}$ Citados en Vargas (2005), pp. 13-14. Véase Djankov, La Porta, López-DE-Silanes y SHLEIFer (2002).

${ }^{144}$ Banco Mundial (2014), p. 178. 
que los procedimientos ordinarios que se tramitan de modo íntegro, es decir, hasta su sentencia definitiva, duran tiempos que en promedio son cercanos a los dos años, que los procedimientos sumarios tienen duraciones sustancialmente inferiores y que la tramitación del recurso de apelación explica una parte muy sustantiva de la duración total. Por supuesto, la valoración de estos resultados no es sencilla y para saber si los plazos son o no razonables habría que tener parámetros de comparación. También sería necesario conocer la complejidad de las causas de que se trata. Pero podemos constatar que, en apariencia, las duraciones descritas están muy por encima de las expectativas de la comunidad legal representada por los diversos autores que se han referido al tema.

Por último, algunos han intentado también avanzar sobre las posibles causas o factores que contribuyen a la lentitud de los procesos. Si bien casi la totalidad de estos estudios parecieran mostrar conciencia sobre problema, la doctrina pareciera ser menos uniforme en este último punto.

En primer lugar, algunos autores han relacionado la lentitud de los procesos al carácter muy escriturado del actual procedimiento civil, y relacionado con lo anterior, por su diseño en aspectos tales como el principio dispositivo, la falta de concentración, el excesivo formalismo, la multiplicidad de recursos, entre otros ${ }^{145}$.

En segundo lugar, otros autores han destacado que la duración también se relaciona con la excesiva carga de trabajo que tendrían los jueces y en cómo estos integran los juzgados en la materia. En este sentido, habría diferencias en el rendimiento que habría entre uno y otro tribunal ${ }^{146}$. Raúl Tavolari, por su parte, añade a los abogados como factor en la lentitud del procedimiento ${ }^{147}$.

En tercer lugar, algunos han mencionado, lo más probable siguiendo a Carlos Cerda, que otro factor crucial en la duración de los procedimientos serían algunas reformas legislativas realizadas durante fines de la década de 1980 y que tuvieron por objetivo simplificar algunos trámites y etapas del proceso ${ }^{148}$.

Finalmente, en particular respecto del procedimiento ejecutivo, el cual como hemos visto ocupa un lugar preponderante en el stock de causas del sistema civil, un estudio realizado por la Pontificia Universidad Católica de Valparaíso para el Ministerio de Justicia y publicado en 2012, señalaba

${ }^{145}$ En este sentido: Harasic (2006), p. 389; Silva y Domínguez (2006), p. 417; OnFraY (2011), p. 78; Villalobos (2009), p. 12. En relación con la falta de una audiencia de preparación y, en particular, en su papel para la conciliación, véase TAVOLARI (1992), p. 163.

${ }^{146}$ Onfray (2010), pp. 169, 172; TAVOlari (1992), pp. 159-160.

${ }^{147}$ Tavolari (1992), pp. 163-168. En este sentido, y desde la óptica del abuso que hacen abogados del principio dispositivo, véase CAROCA (1997), p. 18.

${ }^{148}$ Onfray (2010), p. 172; Tavolari (1992), p. 160; Caroca (1997), p. 18. 
que la lentitud se deberían principalmente a la saturación en la carga de causas que ingresan y conocen los juzgados civiles. Las causas centrales de esta sobrecarga serían las mismas ya citadas en el libro de Raúl Nuñez, Álvaro Pérez Ragone y MacarenaVargas ${ }^{149}$.

\section{CONCLUSiones}

La revisión de todos estos trabajos, que de cualquier modo evalúan o critican nuestro sistema procesal civil en su dimensión práctica, nos lleva a la conclusión de que, al menos en estas áreas, aún no existe la información empírica ni la elaboración doctrinaria suficiente como para realizar un diagnóstico certero y actualizado sobre el funcionamiento real del modelo vigente en el país.

Existe bastante consenso en que el proceso civil presenta problemas de acceso y que resultan excluidos muchos casos, en especial los de grupos sociales más vulnerables. También parece haber acuerdo sobre que el carácter escrito del procedimiento ha generado una serie de prácticas que distorsionan su funcionamiento y a que afectan su confiabilidad. Hay bastantes datos que muestran que los tribunales civiles están copados con 48 casos de cobranzas, que no son complejos y que utilizan la mayor parte de los recursos del sistema. Además, disponemos de antecedentes que dan cuenta de que la duración de los procedimientos parece exceder lo que como comunidad consideramos razonable. No obstante, nuestra opinión y mayor conclusión, es que el presente trabajo da cuenta de que, si bien el conocimiento acumulado logra establecer con claridad algunos aspectos problemáticos del sistema, todavía es necesario avanzar mucho más en algunos aspectos específicos del funcionamiento del sistema que resultan determinantes para el diseño y la toma de decisiones en un eventual proceso de cambio.

Como decíamos, parece estar bien establecido por los trabajos realizados que nuestro sistema presenta problemas importantes de acceso, en especial para sectores vulnerables de la población. Si la reforma aspira a superar esos problemas parece necesario contar con una visión más precisa de estos obstáculos. Por ejemplo, parecería indispensable tener información acerca de los costos de la litigación y de las dificultades para acceder a asesoría letrada. Todas las fuentes indican que ambos elementos lo dificultan fuertemente, pero eso es solo una apreciación general que es necesario precisar con el fin de buscar fórmulas para eliminarlos o superarlos.

${ }^{149}$ NúÑez, Pérez y Vargas (2013), pp. 84-86. 
En relación con el acceso, parece importante contar con información acerca de la demanda potencial que surgiría en el caso de removerse estas barreras. Existen indicios de que hay una demanda insatisfecha que debiera ser cubierta por un sistema reformado. En consecuencia, es necesario saber con cierta precisión en qué consiste esa demanda con miras a diseñar y cuantificar las respuestas que el nuevo sistema debe proveer. Enfrentar a ciegas una demanda potencial e indeterminada genera un enorme riesgo de frustración de expectativas que no debiera correrse.

Una parte muy importante de las críticas al sistema procesal civil vigente se expresa en algunas ideas generales que parecen bastante compartidas, como la de formalismo o delegación de funciones. Si bien es un buen punto de partida, nos parece necesario avanzar de forma sustantiva en el conocimiento de las prácticas específicas que son la base del sistema vigente y que requieren ser cambiadas para dar lugar a uno nuevo y mejor. Requerimos saber con cierto detalle cuáles resultan problemáticas, cuáles son sus causas e incentivos para su permanencia. Si no se comprenden de manera acabada y se atacan directamente, es muy probable que las prácticas problemáticas tiendan a reproducirse en cuanto las condicionantes, que las han generado y sostenido, se mantengan.

También parece claro que las causas civiles se demoran más de lo que nos parece razonable. Si se pretende superar ese problema parece necesario contar con un conocimiento mucho más preciso acerca de las causas de esa demora excesiva. Varios académicos avanzan algunas explicaciones tentativas, tales como problemas de diseño legal o elementos de la cultura legal. Sin embargo, no existe un conocimiento suficientemente profundo al respecto y en consecuencia existe el riesgo de que luego de importantes esfuerzos legislativos, financieros y organizacionales, los problemas de demora se reproduzcan por no haber sido diagnosticados de manera de apropiada.

Los datos del actual sistema dan cuenta de que las causas que de hecho se tramitan corresponden a un padrón bastante homogéneo. No obstante, la remoción de los obstáculos de acceso y la introducción de soluciones más eficientes para las causas sencillas que hoy ocupan al sistema, debieran derivar en un aumento de la heterogeneidad de las causas conocidas por el sistema. Esto supone importantes desafíos vinculados a mejorar las capacidades de otorgar respuestas y soluciones a la conflictividad que se manifieste. Para diseñar las respuestas apropiadas a ese nuevo conjunto más heterogéneo, resulta necesario contar con mayor información sobre el tipo de casos que hoy constituye el relativamente pequeño grupo de casos contenciosos, pero que debiera ampliarse en el futuro. Datos como las cuantías, el tipo y número de partes, el volumen y complejidad de las pruebas a ser utilizadas, resultan indispensables para preparar de forma razonable un escenario apropiado para su manejo. 


\section{BibliografíA}

Banco Mundial (2014). Doing Business 2015. Going Beyond Efficiency, $12^{\text {th }}$ Edition. Washington D.C.: World Bank Group.

Barros Lezaeta, Luis (1997). Opiniones de los sectores populares urbanos en torno a la justicia. Santiago: Centro de Desarrollo Jurídico Judicial, Corporación de Promoción Universitaria.

Caroca, Alex (1997). Derechos humanos y Derecho Civil: Una perspectiva procesal. Santiago: Centro de Desarrollo Jurídico Judicial. Corporación de Promoción Universitaria.

Centro de Estudios de Justicia de las Américas (2011). Estudio de análisis de trayectoria de las causas civiles en los tribunales civiles de Santiago. Informe final. Santiago: Ministerio de Justicia.

Cerda, Carlos (1992). Duración del procedimiento civil ordinario en los juzgados de Santiago. Santiago: FONDECYT.

Cerda, Carlos (1993). Duración del procedimiento civil sumario en los juzgados de Santiago. Santiago: Sin editorial.

Cerda, Carlos (1982a). La realidad del proceso. Vol. I. La oportunidad en el procedimiento ordinario. Santiago: Pontificia Universidad Católica de Chile.

Cerda, Carlos (1982b). La realidad del proceso. Vol. II. La oportunidad en el procedimiento sumario. Santiago: Pontificia Universidad Católica de Chile .

Cerda, Carlos (1982c). La realidad del proceso. Vol. III. La oportunidad en el procedimiento ejecutivo. Santiago: Pontificia Universidad Católica de Chile.

Cerda, Carlos (1997). "Organicidad y funcionalidad de menor y mínima cuantías en el Derecho chileno”. Cuadernos de Análisis Jurídico. Serie Seminarios Nº 33. Santiago: Universidad Diego Portales.

Correa Sutil, Jorge, Carlos Peña y Juan Enrique Vargas (1999). Poder Judicial y mercado. Santiago: Universidad Diego Portales. Informes de Investigación del Centro de Investigación Facultad de Derecho. Año 1. $\mathrm{N}^{\circ} 2$.

Correa Sutil, Jorge y Luis Barros Lezaeta (1993). Justicia y marginalidad, percepción de los pobres. Santiago: Corporación de Promoción Universitaria.

Correa Sutil, Jorge y María Angélica Jiménez (1977). "Sistema judicial y pobreza, estudio sobre el acceso a la justicia en Argentina, Chile, Perú y Venezuela". Cuadernos de Análisis Jurídico. N ${ }^{\circ}$ 35. Santiago: Universidad Diego Portales.

Djankov, Simeon, Rafael La Porta, Florencio Lopez-De-Silanes y Andrei ShleIfer (2002). Courts: The Lex Mundi Project. Cambridge: NBER Working Paper. $N^{\circ} 8890$.

Domínguez, Juan Pablo (2007), "Reflexiones en torno a la propuesta de reforma al procedimiento civil chileno: III. Principios procesales relativos al procedimiento". Revista Chilena de Derecho. Vol. 34. N 3. Santiago. 
EMG Consultores (2012). Estudio de estimación de ingreso de causas para el sistema de justicia civil bajo el actual régimen de funcionamiento. Santiago: Ministerio de Justicia.

Frontaura, Carlos, Francisco Javier Leturia, Javiera Benitez y Pablo Trigo, (2007). "Proyecto pertinencia y posibilidad de implementar juzgados vecinales en Chile", en Camino al bicentenario, propuestas para Chile. Santiago: Universidad Católica de Chile.

García, José Francisco y Francisco Javier Leturia (2006a), "Justicia civil: Diagnóstico, evidencia empírica y lineamientos para una reforma". Revista Chilena de Derecho. Vol. 33. N². Santiago.

GarcíA, Juan Francisco y Francisco Javier Leturia (2006b). "La justicia civil y comercial chilena en crisis: Bases para el diseño de la reforma procesal civil", en José Pedro Silva, Juan Francisco García y Francisco Javier Leturia (eds.). Justicia civil y comercial: Una reforma pendiente. Bases para el diseño de la reforma procesal civil. Santiago: Pontificia Universidad Católica de Chile. Fundación Libertad y Desarrollo.

García, José Francisco y Francisco Javier Leturia (2005). Justicia civil una reforma pendiente. Santiago: Liberad y Desarrollo. Serie Informe Político. N 88.

García, José Francisco y Rodrigo CAStro (2006). Radiografía al trabajo del Poder Judicial. Santiago: Libertad y Desarrollo. Serie Informe Político N 97.

Godoy, Daniela (2009), Mejorando el acceso a la justicia. Santiago: Instituto Libertad.

HaRASIC, Davor (2006), "Justicia civil: Transformación necesaria y urgente", en José Pedro Silva, Juan Francisco García y Francisco Javier Leturia (eds.). Justicia civil y comercial: Una reforma pendiente. Bases para el diseño de la reforma procesal civil. Santiago: Fundación Libertad y Desarrollo. Pontificia Universidad Católica de Chile.

Jiménez, María Angélica, María Inés Horvitz, Juan Enrique VARgas, Jorge Mera y Cristián Riego (1994). Adecuación del proceso penal chileno a las normas de derechos humanos: Informe final del convenio de investigación acordado entre la Corporación Nacional de Reparación y Reconciliación y la Universidad Diego Portales. Santiago: Corporación Nacional de Reparación y Reconciliación.

Jiménez, María Angélica y Cristián Riego (1994). "El proceso penal chileno y los derechos humanos". Cuadernos de Análisis Jurídico. Vol. 2. Santiago: Universidad Diego Portales.

LIRA, Jorge (2012). Antecedentes históricos unidades de justicia vecinal, juzgados vecinales. Santiago: Universidad de Chile.

Marinoni, Luiz, Álvaro Pérez Ragone y Raúl Núñez (2010). Fundamentos del proceso civil. Hacia una teoría de la adjudicación. Santiago: Abeledo Perrot, Legal Publishing.

Mery, Rafael (2006). "Una aproximación teórica y empírica a la litigación civil en Chile", en José Pedro Silva, Juan Francisco García y Francisco Javier Leturia (eds.). Justicia civil y comercial: Una reforma pendiente. Bases para el 
diseño de la reforma procesal civil. Santiago: Fundación Libertad y Desarrollo. Pontificia Universidad Católica de Chile.

Ministerio de Justicia (2011a). Estudio práctico de unidades de justicia vecinal: Diseño de una política pública a partir de la evidencia. Santiago.

Ministerio de Justicia (2012). Proyecto de ley de nuevo Código Procesal Civil, Mensaje presidencial $N^{\circ}$ 432-359. Santiago.

Ministerio DE Justicia (2011b). Resumen ejecutivo: Estudio cuantitativo y cualitativo de los conflictos vecinales y/o comunitarios, y de las alternativas disponibles para su resolución. Santiago: Collect GFK.

NúñEZ, Raúl (2007). "Sobre el avance prelegislativo de la reforma al proceso civil”, en Andrés De La Oliva y Diego Palomo (coords.). Proceso civil. Hacia una nueva justicia civil. Santiago: Editorial Jurídica de Chile.

Núñez, Raúl, Álvaro Pérez Ragone y Macarena Vargas (2013). Hacia una mejor ejecución civil. Rediseño orgánico-procedimental para una justicia más eficiente, transparente, justa y accesible. Santiago: Legal Publishing, Thomson Reuters.

OnfraY, Arturo (2011), "Algunas contribuciones a la reforma de la justicia civil en Chile desde la perspectiva del conflicto", en Francisco Javier LeTURIA (ed.), Justicia civil y comercial: Una reforma ¿cercana? Santiago: Ediciones LYD.

Onfray, Arturo (2010). Civil Justice Reform in Chile. Context, Precedents and Contributions from a Conflict Perspective. Leuven: Katholieke Universiteit Leuven, Faculty of Law.

Onfray, Arturo (1996b), "Proponibilidad, fijación y depuración en los procedimientos civiles de aplicación general". Reforma Procesal Civil (I). Cuadernos de Análisis Jurídicos. Serie Seminarios. N 32. Santiago: Universidad Diego Portales.

OnfraY, Arturo (1996a), "Verificación de la proponibilidad de la acción, fijación y depuración de la litis". Reforma Procesal civil (II). Cuadernos de Análisis Jurídico. Serie Seminarios. $N^{\circ}$ 34. Santiago: Universidad Diego Portales.

Otero, Miguel (2000). Derecho Procesal Civil. Modificaciones a la legislación 19882000. Santiago: Editorial Jurídica de Chile.

PAlomo, Diego (2010), "Apelación doble instancia y proceso civil Oral. A propósito de la reforma en trámite". Estudios Constitucionales. Año 8. No 2. Santiago.

Palomo, Diego (2007). "La prueba en el proceso civil chileno. ¿Una actividad asumida con suficiente seriedad?", en Andrés De La Oliva y Diego Palomo (coords). Proceso civil. Hacia una nueva justicia civil. Santiago: Editorial Jurídica de Chile.

Palomo, Diego (2005), "Proceso civil oral: ¿Qué modelo de juez requiere?". Revista de Derecho. Vol. XVIII. No 1 . Valdivia.

PeñA, Carlos (1993). "Informe sobre Chile". Cuadernos de Análisis Jurídico. Serie $\mathrm{N}^{\circ}$ 2. Santiago: Universidad Diego Portales.

Piedrabuena, Guillermo (1989). "La reforma procesal civil: antecedentes e historia de la Ley 18.705”. Revista Chilena de Derecho. Vol. 16. № 3. Santiago. 
Pontificia Universidad Católica de Valparaíso (2012). Informe final. Diseño de un modelo de oficial de ejecución. Valparaíso: Ministerio de Justicia.

Ried, José Miguel (2006), "Juicio ejecutivo y protección del crédito: Su impacto en el mundo económico y comercial", en José Pedro Silva, Juan Francisco GARCÍA y Francisco Javier LeTURIA (eds.). Justicia civil y comercial: Una reforma pendiente. Bases para el diseño de la reforma procesal civil. Santiago: Fundación Libertad y Desarrollo. Pontificia Universidad Católica de Chile.

Riego, Cristian y Ricardo Lillo (2014). "Las unidades de justicia vecinal en Chile y sus modelos en la experiencia de los Estados Unidos de Norteamérica". Revista de Derecho de la Pontificia Universidad Católica de Valparaíso. XuIII. Valparaíso. $2^{\circ}$ Semestre 2014.

Silva, José Pedro y Juan Pablo Domínguez (2006). "Principios fundamentales del procedimiento civil: diagnóstico y proposiciones a la luz de un nuevo ordenamiento", en José Pedro Silva, Juan Francisco García y Francisco Javier Leturia (ed.), Justicia civil y comercial: Una reforma pendiente. Bases para el diseño de la reforma procesal civil. Santiago: Pontificia Universidad Católica de Chile, Fundación Libertad y Desarrollo.

TAVOlaRi, Raúl (1992), "El proceso civil chileno: Una lectura desde el debido proceso y la eficacia de la jurisdicción de cara a la reforma". Derecho y $\mathrm{Hu}$ manidades. Año 1. $\mathrm{N}^{\circ}$ 2. Santiago.

TAVOLARI, Raúl (1994). Tribunales, jurisdicción y proceso. Santiago: Editorial Jurídica de Chile.

VAlENZuela, Eugenio (coord.) (1991). Proposiciones para la reforma judicial. Santiago: Centro de Estudios Públicos.

VARGAS, Juan Enrique (2006), "Financiamiento de la justicia civil: las tasas judiciales", en José Pedro Silva, Juan Francisco García y Francisco Javier Leturia (eds.). Justicia civil y comercial: Una reforma pendiente. Bases para el diseño de la reforma procesal civil. Santiago: Fundación Libertad y Desarrollo. Pontificia Universidad Católica de Chile.

VARGAS, Juan Enrique (2005). La reforma a la justicia civil desde la perspectiva de las políticas públicas. Santiago: Centro de Estudios de Justicia de las Américas.

VARgas, Juan Enrique y Jorge Correa Sutil (1995). Diagnóstico del sistema judicial chileno. Santiago: Centro de Desarrollo Jurídico Judicial. Corporación de Promoción Universitaria.

Vargas, Juan Enrique, Carlos Peña y Jorge Correa Sutil (2001). "El rol del Estado y el mercado en la justicia". Cuadernos de Análisis Jurídico. Serie Seminarios $\mathrm{N}^{\circ}$ 42. Santiago: Universidad Diego Portales.

VARGAS, Macarena (2013), "Investigación exploratoria sobre la ejecución civil en América Latina”, en Centro de Estudios de Justicia de las Américas. Aportes para un diálogo sobre el acceso a la justicia y reforma civil en América Latina. Santiago. 
VARGAS, Macarena (2011). "Reflexiones en torno a la figura del oficial de ejecución”, en Francisco Javier LETURIA (ed.). Justicia civil y comercial: Una reforma ¿cercana? Santiago: Ediciones LYD.

VIAL, Jorge (2006). Informe sobre desjudicialización de competencias en materia civil. Santiago: Pontificia Universidad Católica de Chile. Facultad de Derecho.

Villalobos, Sergio (2009). "Génesis y necesidad de una reforma procesal civil". Entheos. Año 7. Vol. único. Santiago. 